(c) The Author(s), 2022. Published by Cambridge University Press on behalf of The Nutrition Society. This is an Open Access article, distributed under the terms of the Creative Commons Attribution licence (http://creativecommons.org/licenses/by/4.0/), which permits unrestricted re-use, distribution and reproduction, provided the original article is properly cited.

\title{
Vegans and vegetarians living in Nottingham (UK) continue to be at risk of iodine deficiency
}

\author{
Elizabeth Eveleigh, Lisa Coneyworth, Mi Zhou, Hannah Burdett, Jhama Malla, Van Hoang Nguyen and \\ Simon Welham* \\ Division of Food, Nutrition \& Dietetics, School of Biosciences, The University of Nottingham, Sutton Bonington LE12 5RD, UK \\ (Submitted 18 May 2021 - Final revision received 24 November 2021 - Accepted 11 January 2022 - First published online 21 January 2022)
}

\section{Abstract}

Iodine is essential for thyroid hormone synthesis. Individuals adhering to vegan and vegetarian diets have been found to be vulnerable to iodine deficiency. Yet, iodine has not been monitored in these groups across time. This study aims to investigate iodine status, intake and knowledge in vegans, vegetarians and omnivores and determine changes between 2016-2017 and 2019. Dietary intake ( $\mu \mathrm{g} / \mathrm{d}$ ) was estimated by 3-d food diaries and iodine FFQ. Urinary iodine concentration, analysed by inductively coupled plasma mass spectrometry, assessed iodine status according to WHO criteria. Iodine knowledge was scored by an adapted questionnaire. IBM SPSS was used for statistical analysis. Ninety-six adults (18-60 years) were recruited in October 2016-2017 (vegans: 12; vegetarians: 5; omnivores: 43) and June 2019 (vegans: 7; vegetarians: 10;omnivores: 19). Median dietary iodine was below the Reference Nutrient Intake for all groups. Vegans and vegetarians had the lowest iodine intake. Vegans had significantly lower iodine intake than omnivores (2016-2017, $P=0032 ; 2019, P=0001)$. Omnivores had the highest iodine status (2016-2017, $794 \mu \mathrm{g} / \mathrm{l} ; 2019,724 \mu \mathrm{g} / \mathrm{l})$ and vegans the lowest (2016-2017, $312 \mu \mathrm{g} / \mathrm{l} ; 2019,122 \mu \mathrm{g} / \mathrm{l})$. Iodine knowledge was poor but did not differ between dietary groups (2016-2017, $P=0$ 219; 2019, $P=0$ 532). Vegans and vegetarians continue to be at risk of iodine deficiency. Further, iodine intake in the UK is poor independent of dietary choice. Iodine education is needed along with research into improving iodine nutrition at national level.

Key words: Iodine: Vegan: Vegetarian: Micronutrient deficiency

Iodine is an essential micronutrient required to produce thyroid hormones, thyroxine (T4) and triiodothyronine (T3) ${ }^{(1)}$. Thyroid hormones are necessary for normal neuronal development, metabolic function and growth throughout the lifespan ${ }^{(1)}$. Iodine deficiency occurs when physiological requirements are not met, and thyroid hormone synthesis is low ${ }^{(2)}$. Deficiency can result in a series of clinical abnormalities termed 'iodine deficiency disorders' and is most obviously manifested with the appearance of a goitre, the enlargement of the thyroid gland $^{(1-3)}$. In pregnancy, risk of stillbirth, spontaneous abortion and other birth defects are increased in iodine deficient states ${ }^{(3)}$. Infants exposed to deficiency in utero are at risk of impaired cognitive development resulting in irreversible neurological damage, leading to cretinism in its most severe form ${ }^{(1-3)}$. Coexisting deficiencies of micronutrients such as $\mathrm{Fe}$, Se and vitamin A may further impair iodine absorption and thyroid hormone production ${ }^{(4)}$. Deficiency, attributed to insufficient dietary iodine intake, is recognised as a major public health problem $^{(5)}$
The WHO recommends a Reference Intake of $150 \mu \mathrm{g} / \mathrm{d}$ for adults ( $>12$ years), in order to optimise thyroid hormone production (typically requiring around $70 \mu \mathrm{g} / \mathrm{d}$ ) ${ }^{(6,7)}$. In the UK, a lower Reference Nutrient Intake (RNI) of $140 \mu \mathrm{g} / \mathrm{d}$ has been selected to ensure that $97.5 \%$ of the population meets iodine intake ${ }^{(8)}$. Historically, iodine deficiency was prevalent in the UK, with some regions experiencing endemic goitre ${ }^{(9)}$. Eradication began in the 1960s due to government campaigns encouraging milk consumption, and changes in farming practice resulting in production of milk with a higher iodine content ${ }^{(10)}$. For many years following intervention, intake was considered sufficient, but is now a recognised public health issue after mild iodine deficiency was detected in schoolgirls and pregnant women in 2014-2015 ${ }^{(9,11)}$. More recently, iodine intake was recognised as of concern for UK adults following a secondary analysis of the UK National Diet and Nutrition Survey in $2018^{(12)}$. Iodine intake estimates for males and females (aged 20-59 years) were recorded to be significantly lower than the current RNI. Young adults (aged 20-29 years) were recognised to be substantially

Abbreviations EE, energy expenditure; FD, food diaries; PAL, physical activity level; RNI, Reference Nutrient Intake; UIC, urinary iodine concentration.

* Corresponding author: Dr S. Welham, fax +44 115951 6122, email simon.welham@nottingham.ac.uk 
more at risk than older adults (aged 30-59 years), with $15 \%$ of males and $17 \%$ of females falling below the Lower Reference Nutrient Intake for iodine. Recent studies suggest that lack of information and knowledge regarding iodine may be greater in individuals at risk of iodine deficiency ${ }^{(13-15)}$. Current trends in food avoidance and dietary restriction, particularly of meat and dairy, have been recognised as a factor contributing to lowered iodine intake ${ }^{(16)}$. Individuals who have low knowledge and are not aware of the importance of adequate iodine intake may be less well equipped to make dietary changes that permit them to meet their iodine requirements.

In the UK, the main sources of dietary iodine are cows' milk and dairy products ${ }^{(17)}$. Seafood, eggs, seaweed and iodine-containing supplements are also iodine rich $^{(17)}$. The relative iodine content of foods commonly consumed in the UK is presented in Table 1. Despite being the primary source of iodine, milk consumption has reduced considerably over the last decade. Particularly in those aged 16-24 years, whose cows' milk consumption has declined rapidly in recent years ${ }^{(18)}$. The proportion of people in this age group consuming cows' milk decreased from 79 to $73 \%$ between years 2018-2019 $9^{(18)}$. This decrease could reflect the growth and appeal of the alternative milk market in the UK. Food purchasing data from average UK households indicated an upwards trend in purchasing of alternative milks since 2014 (Table 2) ${ }^{(19,20)}$. Alternative milks such as soya, oat and coconut are now regularly consumed, very

Table 1. Average iodine content of foods consumed regularly in the UK per food portion

\begin{tabular}{|c|c|c|c|}
\hline Food & Serving size (ml/g) & Average iodine/portion $(\mu \mathrm{g} / \mathrm{g})$ & $\begin{array}{l}\text { Contribution of food groups to average daily iodine } \\
\text { intake by NDNS (2016-2017 to 2018-2019) (\%) }\end{array}$ \\
\hline \multicolumn{4}{|l|}{ Milk and dairy products } \\
\hline Cows' milk (semi-skimmed) & 200 & $50-100^{*}, \dagger$ & $13 \|$ \\
\hline Organic cows' milk (semi-skimmed) & 200 & $30-60^{*}, \dagger$ & NA \\
\hline Yogurt & 150 & $50-100^{*}, \dagger$ & $6 \|$ \\
\hline Cheese & 40 & $15 \dagger$ & $3 \|$ \\
\hline \multicolumn{4}{|l|}{ Fish and seafood } \\
\hline Whitefish (haddock and cod) & 120 & 230-390† & $8 \|$ \\
\hline Salmon & 100 & $14 \dagger$ & NA \\
\hline Tinned tuna & 100 & $12 \dagger$ & NA \\
\hline Prawns & 60 & $6+$ & NA \\
\hline \multicolumn{4}{|l|}{ Eggs, meat and poultry } \\
\hline Eggs & 50 & $25 \dagger$ & $9 \|$ \\
\hline Meat and poultry & 100 & $10 \dagger$ & $9 \|$ \\
\hline \multicolumn{4}{|l|}{ Plant based } \\
\hline Fortified alternative milk & 200 & $53-57 \ddagger$ & NA \\
\hline Unfortified alternative milk & 200 & $1-4 \ddagger$ & NA \\
\hline Nuts & 25 & $5 \dagger$ & 0 \\
\hline Bread & 36 & $5 \dagger$ & 3 \\
\hline Fruit and vegetables & 80 & $3+$ & 6 \\
\hline Nori seaweed & 26 & $382 \S$ & NA \\
\hline
\end{tabular}

NA, not applicable.

${ }^{*}$ Actual iodine content subject to seasonal variation (winter $=$ higher) and organic farming practices (organic $=$ lower).

$\dagger$ Data from the British Dietetic Association (BDA) lodine Fact Sheet ${ }^{(17)}$.

$\ddagger$ Data from Bath et al. ${ }^{(21)}$.

§ Data from Nutritics database UK (2015 COFIDS including McCance and Widdowson 7th edition, 2015) ${ }^{(40,41)}$

|| Data from NDNS Y9-11 Descriptive statistics tables (19-64 years used $\left.{ }^{(42)}\right)$.

Table 2. Purchasing data and trends from UK households: Family Food 2018-2019 Living Costs and Food Survey (LCFS) ${ }^{(19,20)}$

\begin{tabular}{|c|c|c|c|c|c|c|c|}
\hline Food item $(\mathrm{g} / \mathrm{d})$ & $\begin{array}{c}2015- \\
2016\end{array}$ & $\begin{array}{c}2016- \\
2017\end{array}$ & $\begin{array}{c}2017- \\
2018\end{array}$ & $\begin{array}{c}2018- \\
2019\end{array}$ & $\begin{array}{l}\text { Change from } 2015-2016 \text { to } \\
2016-2017(\%)\end{array}$ & $\begin{array}{c}\text { Change from } 2016-17 \text { to } \\
2017-2018(\%)\end{array}$ & $\begin{array}{c}\text { Trend between } \\
2017-2018 \text { and } \\
2018-2019\end{array}$ \\
\hline $\begin{array}{l}\text { Cows' milk and milk } \\
\text { products } \dagger\end{array}$ & 258.09 & $259 \cdot 78$ & $255 \cdot 17$ & $262 \cdot 80$ & +2 & +3 & - \\
\hline $\begin{array}{l}\text { Semi-skimmed cows' } \\
\text { milk }\end{array}$ & 134.99 & $135 \cdot 78$ & 132.05 & 128.98 & -4 & -2 & - \\
\hline $\begin{array}{l}\text { Yogurt and fromage } \\
\text { frais }\end{array}$ & $27 \cdot 55$ & 28.52 & $26 \cdot 88$ & $28 \cdot 41$ & -3 & +6 & - \\
\hline Cheese & $16 \cdot 46$ & $17 \cdot 69$ & $17 \cdot 82$ & $17 \cdot 64$ & +7 & -1 & $\uparrow$ \\
\hline Fish & $20 \cdot 64$ & $19 \cdot 86$ & $19 \cdot 79$ & $20 \cdot 81$ & +1 & +5 & - \\
\hline Whitefish $\ddagger$ & $2 \cdot 51$ & 1.95 & $2 \cdot 21$ & $2 \cdot 10$ & -16 & -5 & - \\
\hline Eggs & 0.28 & 0.28 & 0.28 & 0.3 & +9 & +6 & $\uparrow$ \\
\hline Dairy milk alternatives & $5 \cdot 86$ & $7 \cdot 15$ & $9 \cdot 38$ & $9 \cdot 85$ & +71 & $\rightarrow+5 \rightarrow$ & $\uparrow$ \\
\hline
\end{tabular}

† Excluding cheese.

‡ Fresh, chilled or frozen. Upward arrows show significant increases in UK purchasing between 2017-2018 and 2018-2019 $(P=<0.05)$.

No significant change in purchasing trends $2017-2018$ and 2018-2019 $(P \leq 0.05)$. 
low in iodine and not regularly iodine fortified ${ }^{(21)}$. Although iodine rich, the contribution of fish and seaweed to iodine intake in the UK is likely to be small reflecting low national consumption $^{(22)}$. The iodine content of seaweed is highly variable and if not monitored in the diet, over-consumption could induce excess iodine intake ${ }^{(23-25)}$. Many countries implement mandatory or voluntary iodised salt legislation ${ }^{(26)}$. Fortified salt used at household level provides additional dietary iodine and has been shown to alleviate deficiency ${ }^{(27)}$. Routine salt iodisation is not present in the UK currently and access to iodised salt in supermarkets is low ${ }^{(28)}$. Even if table salt was fully iodised, it is unlikely to provide adequate dietary iodine as table salt only comprises a small proportion (15\%) of dietary sodium consumed in the UK diet, and over half of intake $(>60 \%)$ is provided by ready-made and processed foods ${ }^{(29,30)}$.

Inadequate iodine intake has been observed in individuals who consume diets excluding iodine-rich foods, principally dairy and/or fish ${ }^{(31)}$. For this reason, vegans and vegetarians are recognised as a subgroup with increased risk of iodine deficiency ${ }^{(16)}$, as confirmed by recent research conducted in European nations including the UK, Germany, Finland, Norway, Spain and Switzerland ${ }^{(32-39)}$.

Despite the increasing acceptance of vegan and vegetarian diets in the UK and the emergence of iodine deficiency, there is a lack of data regarding the level of iodine knowledge and whether good understanding of the challenges allows individuals to account for iodine when dietary restrictions are implemented. The purpose of this study was to investigate iodine status, intake and knowledge in vegans, vegetarians and omnivores and determine if changes were observed with time (between 2016 and 2019). We hypothesised that iodine intake and status would be positively associated with knowledge and that deficiency would be greater in vegans and vegetarians lacking good understanding compared with omnivores. We additionally proposed that, since a greater array of specialist foods would be available in 2019 than in 2016, iodine intake and status would be improved in vegans and vegetarians in the more recent cohort.

\section{Methods}

\section{Ethical approval}

This study was conducted according to the guidelines laid down in the Declaration of Helsinki and all procedures involving human subjects/patients were approved by the Faculty of Medicine \& Health Sciences Research Ethics Committee Nottingham University Hospitals (Ethics Reference No. BS02082016). Written informed consent was obtained from all subjects.

\section{Design and recruitment}

Students and staff of The University of Nottingham ( $n$ 96) were recruited to the study at two separate time points, 2016-2017 and 2019. The first phase of recruitment was conducted between 24 October 2016 and 01 January 2017 and the second 16 June and 13 November 2019. The study protocol is outlined

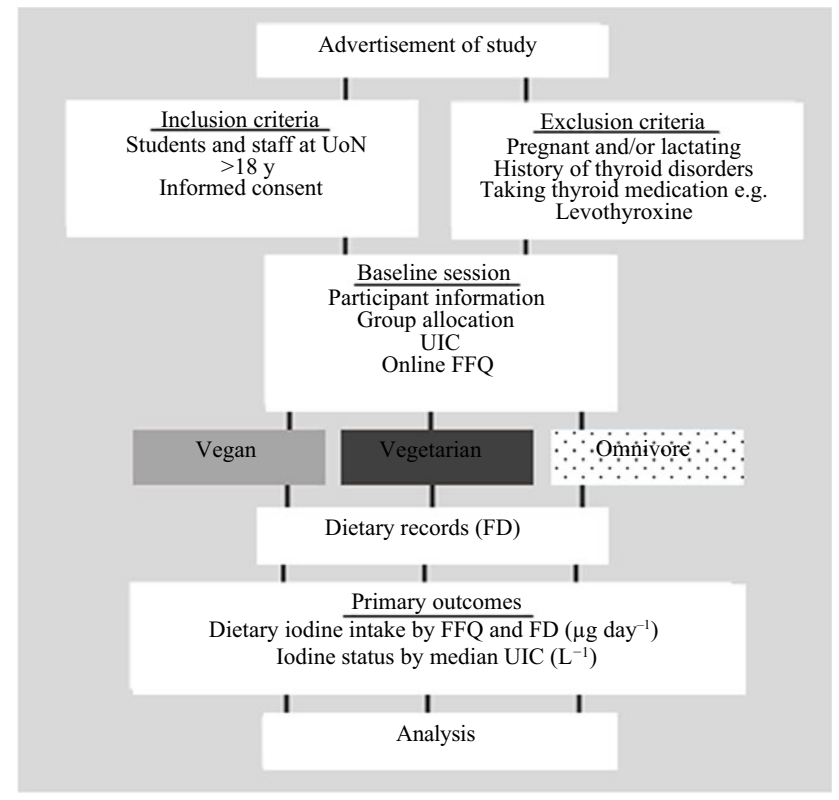

Fig. 1. Flow chart of study protocol. UIC, urinary iodine concentration. FD, food diary.

in Fig. 1. The study was advertised using posters, leaflets and emails distributed throughout the university. Adults following vegan and vegetarian diets were recruited by social media advertisement circulated through university societies.

Participants matching the inclusion criteria were invited to attend a one-off session at 12.00 hours each day, whereby the experimental methodology was explained, and baseline data collected. To maintain anonymity, a unique participant number was randomly selected at baseline. During these sessions, individuals were provided with a participant information pack containing the study information sheet, 3-d food diary (FD), weblink to an online FFQ, a sterile universal urine tube and an ID number unknown to researchers. Participation was optional and written informed consent was obtained.

\section{Dietary grouping}

Participants were categorised into three dietary groups: vegan, vegetarian and omnivore, based on responses to the online FFQ addressing current dietary preference and consumption of animal products in the past 6 months. Participants who reported no dietary restrictions relating to animal products were classified as omnivores. Participants who did not consume animal products of any form were classified as vegans. Vegetarians encompassed all descriptions of vegetarian diets and were those who consume milk, eggs and possibly fish (pescatarians) but not meat. The vegetarian group also comprised individuals who had recently $(<3$ months) transitioned from vegetarian to a vegan diet.

\section{Assessing dietary iodine intake}

Dietary iodine consumption was assessed using an online FFQ and 3-d FD introduced during baseline sessions. Adequate 
iodine intake was assessed using the current UK RNI of $140 \mu \mathrm{g} / \mathrm{d}$ and Lower Reference Nutrient Intake of $70 \mu \mathrm{g} / \mathrm{d}^{(8,16)}$.

\section{FFQ}

The FFQ was developed using 'Online surveys' (previously 'Bristol Online Surveys' ${ }^{(43)}$ ) to assess habitual dietary intake over the past 6 months and was based on the validated FFQ used in the Oxford component of the European Prospective Investigation into Cancer and Nutrition (EPIC Oxford) study ${ }^{(44)}$. The FFQ addressed forty-five different food items including sources of dietary iodine and goitrogenic foods (online Supplementary Table S1). Prior to study, the FFQ was modified to address dietary preference and consumption of substitutes of specific foods that could be a potential source of iodine for those following vegan and vegetarian diets, such as alternative milk and dairy products. Frequently consumed food items, such as cows' milk, were listed in separate questions accounting for variations in serving sizes. Medium serving size was indicated using labelled food images employed by the National Diet and Nutrition Survey ${ }^{(45)}$ (online Supplementary Fig. S1). For each food item, frequency categories were converted to daily iodine intake $(\mu \mathrm{g} / \mathrm{d})$. The category: ' 2 to 4 times/week' was adjusted to three per week or equivalent to 0.4 servings/d. It was assumed that those selecting the 'Less than once or never' option for rare foods such as samphire or animal products for vegans were not consumed within the past 6 months, thus generating a value of $0 \cdot 0$. Food items were assigned iodine values per portion from an in-house database created using data from Nutritics 4.3 software and McCance and Widdowson's composition of foods integrated dataset $^{(40,41)}$

\section{Three-day food diary}

Iodine consumption was measured by a 3-d FD based on that used in the National Diet and Nutrition Survey ${ }^{(46)}$. Participants were asked to record estimated daily food and drink consumption, including descriptions of relative portion sizes, brand names of packaged items, home-cooked meal ingredients and supplement intake. Further questions addressed fluctuation from usual dietary patterns to establish if recorded intakes reflected that of a normal day. Participants were asked to complete the FD in the three consecutive days following recruitment sessions. To reduce disparity in diet patterns between the week and weekends, sessions were organised so that FD records contained at least one weekend day. If the consecutive days after recruitment did not contain a weekend, completion was postponed. Participants were asked to return completed FD to accessible drop-off points. Nutritics 4.3 was used to estimate dietary intakes. Databases used were limited to include food values of UK foods only. Average portion sizes for items designated by Nutritics were selected if not specified by participants. It was assumed that, unless stated, all milk was semi-skimmed nonorganic cows' milk, alternative milks were unfortified unless brand information or fortification status was specified and salt added to meals was non-iodinated. Best estimates were made for vegan substitutes of food items not listed on Nutritics software using online information from retailers or back-of packet values. Recipes from the Vegan Society were used to calculate iodine values for vegan compound foods, such as cakes and biscuits, where there was no viable substitution in UK databases. All analysis considered edible portions for analysis and adjusted for cooking procedure when required. Where possible, Nutritics food codes with values for iodine were selected. Iodine values were added manually using data from Nutritics if the selected food code was established from label-based analysis. Nutritics outputs from FD were used to calculate the average quantity $(\mathrm{g})$ of iodine-rich foods consumed and the contribution (\%) of food groups to total iodine intake.

\section{Assessing iodine status}

Urinary iodine concentration. Optional spot urine samples were collected to determine median urinary iodine concentration (UIC). Participants were asked to complete a $50 \mathrm{ml}$ single spot urine sample during information sessions to reduce diurnal variation associated with estimates. Samples were centrifuged immediately after collection at 914 relative centrifugal force for 5 min (Beckman GS-6R Refrigerated Centrifuge GS1M31) and supernatant frozen at $-80^{\circ} \mathrm{C}$. Samples were defrosted overnight at $4{ }^{\circ} \mathrm{C}$. UIC was determined using inductively coupled plasma mass spectrometry (Thermo Fisher Scientific). Known iodine concentrations were used as a control during analysis. Standards and samples were diluted 1:10 with Milli-Q $\mathrm{H}_{2} \mathrm{O}$, transferred to analysis tubes and analysed in triplicate.

Classification of status. The WHO criteria were used to assess iodine status using UIC expressed as a median with inter-quartile range $^{(6)}$. Groups with median with UIC $>100 \mu \mathrm{g} / \mathrm{l}$ were considered 'sufficient' and those with values $<100 \mu \mathrm{g} / \mathrm{l}$ were considered 'deficient'. Relative levels of deficiency were classified as: 50-99 $\mu \mathrm{g} / \mathrm{l}$ mild, 20-49 $\mu \mathrm{g} / \mathrm{l}$ moderate and $>20 \mu \mathrm{g} / \mathrm{l}$ severe.

lodine knowledge and demographic data. The FFQ additionally collected demographic information which may contribute to iodine status, including ethnicity, educational level, degree classification, employment status, smoking status and alcohol consumption. Participants were also asked to complete seven questions addressing iodine knowledge and factors influencing iodine nutrition, generating a total possible score of 17 (online Supplementary Table S2). Questions were modified from studies previously investigating iodine knowledge in the $\mathrm{UK}^{(14)}$. Negative marking was used and a point was deducted for each incorrect answer, this was so that individuals were discouraged from selecting all listed responses. Iodine knowledge was considered 'poor' if scores were 5 or below, 'fair' if between 5 and 10 and 'good' if above 10.

Anthropometric data. All measurements of height $(\mathrm{cm})$ and weight $(\mathrm{kg})$ were self-recorded as part of the FFQ. BMI (weight $/$ height ${ }^{2}, \mathrm{~kg} / \mathrm{m}^{2}$ ) was determined and classified according to the WHO assessment ${ }^{(47)}$.

Assessing under-reporting. FD estimates were used to assess under-reporting. FFQ could not be used as energy intake was not estimated. Schofield equations were applied to determine the ratio between BMR or energy expenditure (EE) and actual 
reported intake (EIrep:EE) using age and weight $(\mathrm{kg})$ as a reference $^{(48)}$. To identify records of poor validity, participants were classified according to EIrep:EE into under-reporters, acceptable reporters and over-reporters using the Goldberg cut-off ${ }^{(48,49)}$. Activity levels were not assessed during this study; therefore, a lower activity factor was used to calculate the estimated energy requirement. A physical activity level (PAL) of 1.5 was used for adjustment ${ }^{(50)}$. This value describes a population with a low level of daily physical activity (not sick, disabled or elderly).

The calculations used to determine cut-offs were

$$
95 \% \text { Confidence limits }=\mathrm{PAL} \times \exp ( \pm 2 \times((\mathrm{S} / 100) / \sqrt{ } \mathrm{n})
$$

where, PAL is equal to $1.5 ; \mathrm{n}$ is the participant no (45) and $\mathrm{S}$ is the factor accounting for variation in estimated intake (EI), BMR and PAL was estimated by:

$$
\mathrm{S}=\sqrt{ }(\mathrm{CV} 2 \mathrm{wEI} / \mathrm{d}+\mathrm{CV} 2 \mathrm{wB}+\mathrm{CV} 2 \mathrm{tP})
$$

where, CVwEI is the within-subject variation in EI in our cohort ( $28 \%$ ); D is the number of days of dietary assessment (3 d); $\mathrm{CVwB}$ is the variation in repeat BMR measures (9\%) and CVtP is the total variation in PAL (15\%).

The CV for within-individual variation for our cohort was determined as $18 \%$. CV parameters (9 and 15\%) were taken from those generated by Black ${ }^{(48)}$ and have been accepted as suitable for use in the Goldberg equation. CI at $95 \%$ were applied; those with EIrep:EE of 1.41-1.71 were considered as acceptable reporters. Participants with values $<1.41$ were under-reporters and $>1.71$ as over-reporters.

Statistical analysis. Data analysis was performed using IBM SPSS Statistics V22.0. A significance of $P<0.05$ (two-tailed) was selected for all statistical analysis. Normality of the data was assessed using the Shapiro-Wilk test for normality. UIC and dietary iodine intake values were not normally distributed; therefore, medians are reported. Kruskal-Wallis H tests with Dunn's post hoc tests were performed to compare intake and status where groups were two or more. Spearman's rank correlation was used to determine relationships between continuous data. Pearson's $\chi^{2}$ test was used for comparison between categorical variables. The Bonferroni test for adjustment was used for correction. Sample size estimates were calculated based upon data obtained from a previous report which provided mean and standard deviation measurements for vegans and omnivores $^{(51)}$. The effect size was recorded as $106 \mu \mathrm{g} / \mathrm{d}$ with a population standard deviation of $91 \mu \mathrm{g} / \mathrm{d}$ and a recruitment bias of 1 . For a power of $80 \%$ and an $\alpha$-error of $5 \%$, the sample size was calculated as a minimum of 24 ( 12 per group) for vegans and omnivores using the 'ClinCalc' online calculator ${ }^{(52)}$.

\section{Results}

\section{Study population}

Descriptive characteristics of participants ( $n$ 96) are listed in Table 3. Two individuals in 2019 (one male and one female) had recently transitioned onto a vegan diet and were considered

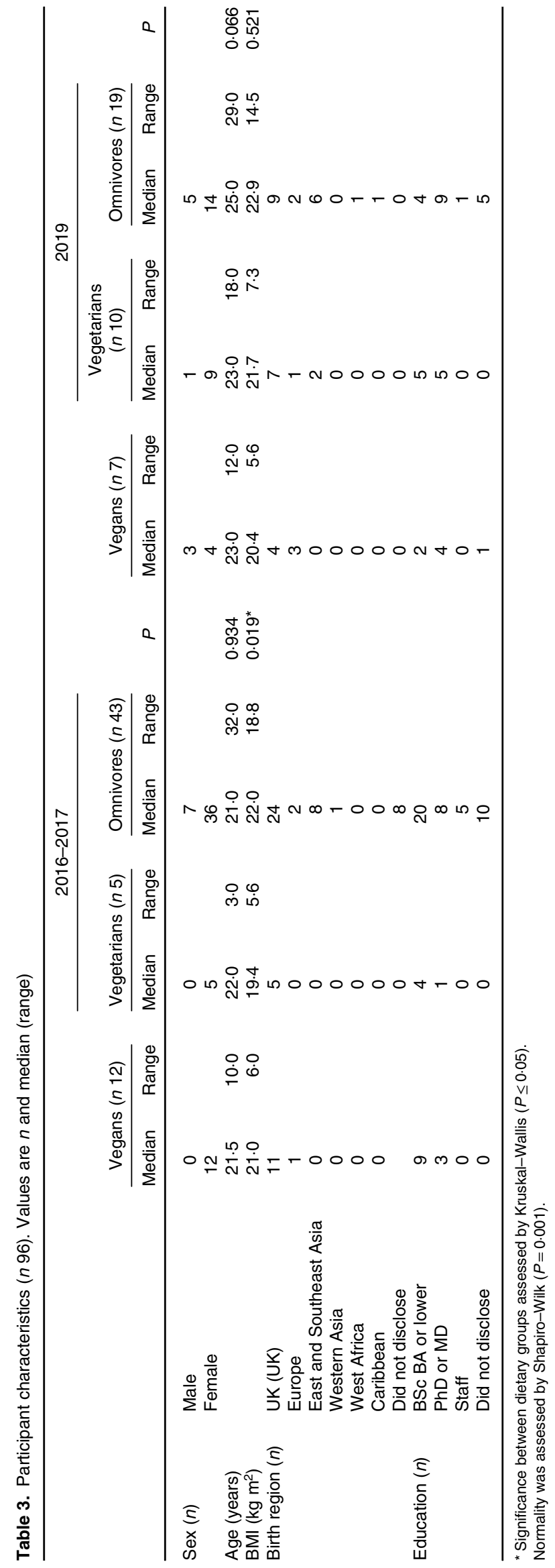


as vegetarians. All dietary groups were predominantly composed of females ( $84 \%$ ). The average BMI for each dietary group was lower than the UK population ${ }^{(50)}$, but within the healthy range (18.5-24.9) for most participants. Exceptions included six overweight female omnivores (BMI; overweight: 25.0-29.9), as well as two female vegetarians and one female vegan who were below the normal range of BMI (17.0, 16.6 and $18 \cdot 2$, respectively). BMI values were significantly lower in vegetarians than omnivores in 2016-2017 $(P=0 \cdot 019)$. In 2019, there was no difference in BMI between dietary groups $(P=0.066)$. We were unable to assess differences in sex, nationality and qualifications by $\chi^{2}$ as the minimum expected count was under 5 for these variables.

\section{Dietary intake}

Other specific diets were followed by three vegans in 2016-2017, two of which avoided starch and bread/flour products and one described having a lactose intolerance. Lactose intolerance was reported by one omnivore in 2019 .

The prevalence of under-reporting was high in both years with $73 \%$ of participants recording an EIrep:EE ratio $<1.41$. All male participants were classified as under-reporters, but under-reporting did not differ between dietary groups with vegans, vegetarians and omnivores having similar occurrence (2016-2017; 75, 50 and $68 \%, P=0 \cdot 830$ ). In 2019, under-reporting was more prevalent, with $100 \%$ of vegans being classed as under-reporters compared with $71 \%$ of vegetarians and $86 \%$ of omnivores $(P=0.608)$. In both years, vegetarians had the largest proportion of acceptable-reporters (2016-2017: 50\%; 2019, $28 \%$ ), while none of the vegan participants in 2019 had values within this range. Over-reporting was low in both years, with none recorded in 2019 compared with two omnivores and one vegan in 2016-2017.

Energy intake did not differ between dietary groups (2016-2017, $P=0.438 ;$ 2019, $P=0.802$, Table 4). We were unable to stratify by sex due to low numbers of males in our cohort. However, with the inclusion of males, average energy intake was greater than current estimates of the UK population for females ( $1632 \mathrm{kcal})$ but not males $(2313 \mathrm{kcal})$ for most dietary groups ${ }^{(53)}$. In both years, vegans had the greatest daily energy intake (2016-2017, $1755.3 \mathrm{kcal} ; 2019,1656.0 \mathrm{kcal})$. There was no relationship between energy and iodine intake by FD or FFQ in 2016-2017 or 2019 (FD, $r 0.085, \quad P=0.610$; FFQ, $\quad r 0.044, P=0.796$ and FD, $r 0.067, P=0.786 ; \quad \mathrm{FFQ}$, $r 0.012, P=0.960)$.

Average daily intake of macronutrients by dietary group is presented in Table 4 . In both years, vegans consumed significantly greater quantities of fibre than omnivores (2016-2017, $P<0.001 ; 2019, P=0.030)$. In 2016-2017, polyunsaturated fat intake was significantly higher in vegans compared with omnivores $(P=0 \cdot 011)$.

\section{Dietary iodine}

Median iodine intake estimated by FFQ and FD is shown in Fig. 2. Intakes derived from the FFQ were higher $(P=0.020)$ and displayed larger variation than those provided by FD.

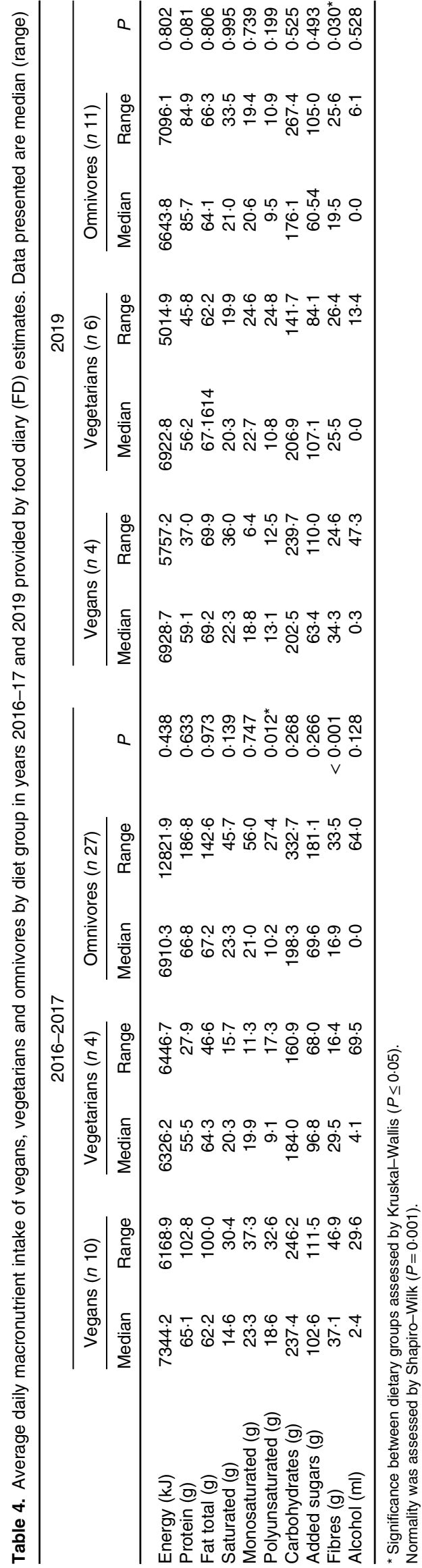



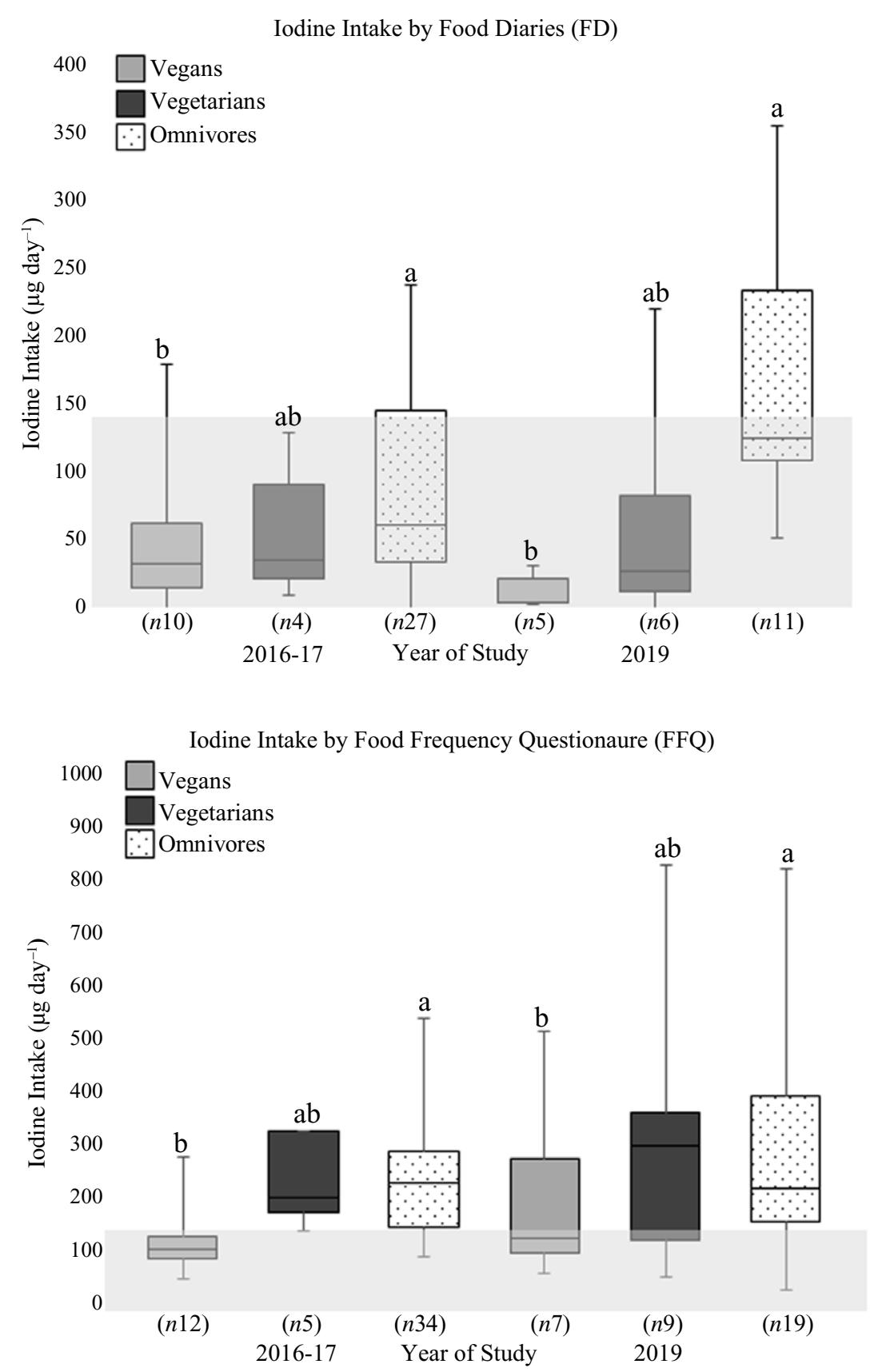

Fig. 2. Estimated dietary iodine intake by FFQ and food diaries (FD) for vegans, vegetarians and omnivores. Shaded areas represent intakes below the Reference Nutrient Intake (RNI) of $140 \mu \mathrm{g} / \mathrm{d}$. Different letters $(\mathrm{a}$ and $\mathrm{b})$ represent significant differences among dietary groups, whereby $a>b, a b=a, a b=b, a>c, b>c$ and ab $>$ c $(P \leq 0.05)$ (Kruskal-Wallis test).

lodine intake by food diary

Median iodine intake was below the RNI $(150 \mu \mathrm{g} / \mathrm{d})$ for all dietary groups in 2016-2017 (vegans: $47.6 \mu \mathrm{g} / \mathrm{d}$; vegetarians: $68.8 \mu \mathrm{g} / \mathrm{d}$ and omnivores: $111.9 \mu \mathrm{g} / \mathrm{d}$ ) and 2019 (vegans: $17.3 \mu \mathrm{g} / \mathrm{d}$; vegetarians: $71.4 \mu \mathrm{g} / \mathrm{d}$ and omnivores: $126 \cdot 0 \mu \mathrm{g} / \mathrm{d}$ ) (Fig. 2). The RNI was not achieved by any vegetarians in 2016-2017 or vegans in 2019. Median values for vegans and vegetarians in 2016-2017, and vegans in 2019, were below the Lower Reference Nutrient Intake of $70 \mu \mathrm{g} / \mathrm{d}$. More than $75 \%$ of participants had values associated with severe deficiency. Average iodine intake in vegans and vegetarians was lower than current estimates of the UK population of $98 \mu \mathrm{g} / \mathrm{l}$ for women of childbearing age (19-49 years) and $106 \mu \mathrm{g} / \mathrm{l}$ for adults (19-64 years).

Inadequate intake was more frequent in those following vegan and vegetarian diets than omnivorous diets. In both years, median intake was numerically lower in vegan and vegetarian groups and was significantly lower in vegans compared with omnivores both years (2016-2017, $P=0.032 ; 2019$, $P=0.001$ ) 


\section{lodine intake by FFQ}

In both years, FFQ median dietary iodine intake for vegetarians and omnivores was above the RNI (2016-2017, $202.9 \mu \mathrm{g} / \mathrm{d}$, $299.6 \mu \mathrm{g} / \mathrm{d} ; 2019,230.0 \mu \mathrm{g} / \mathrm{d}, 221.9 \mu \mathrm{g} / \mathrm{d})$. Dietary iodine intake for vegans did not meet the RNI (2016-2017, $107 \cdot 0 \mu \mathrm{g} / \mathrm{d}$, $124.9 \mu \mathrm{g} / \mathrm{d}$ ). Intakes between dietary groups displayed a similar trend as observed in FD. In 2016-2017, median values were significantly lower in vegans compared with omnivores $(P<0.001)$. This trend was not seen in vegetarians, whose intake in 2016-2017 was similar to those of omnivores $(P=1 \cdot 000)$. In 2019 , no significant differences in iodine intake were observed between dietary groups $(P=0 \cdot 356)$.

\section{Sources of iodine}

We assessed the average daily consumption of foods potentially contributing to iodine intake using data from FD (Table 5). In both years, omnivores had the greatest consumption of cows' milk, dairy products and eggs. In 2019, fish and seafood were predominantly consumed by omnivores. Seaweed was only consumed as a supplement by two omnivores and is not considered a regular dietary source of iodine. In 2016-2017, alternative milk, alternative milk product and seaweed consumption were significantly greater in vegans than omnivores $(P=0.001,0.016$ and 0.040$)$. No significant differences in iodine-rich food consumption were observed between dietary groups for either year when non-consumers were removed from analysis.

\section{Food group contribution to iodine}

The major sources of dietary iodine in each cohort are displayed in Table 6. In 2016-2017, the food groups contributing the largest proportion to iodine intake in omnivores were cows' milk (21\%) and eggs (10\%). In 2019, cows' milk (24\%) and fish and seafood $(12 \%)$ were major sources of dietary iodine. Cows' milk was a key source of iodine in the diets of vegetarians in both years rising from $10 \%$ in $2016-2017$ to $14 \%$ in 2019 . Eggs were also a good source of iodine in the diets of vegetarians in 2016-2017 but not 2019 (7 and $0 \%$, respectively).

Plant-based sources were the major providers of iodine for vegans. Fruit and vegetables being the predominant source (21 and $27 \%$ ), followed by breads, grains and pulses ( 5 and $22 \%$ ). Unlike cows' milk and dairy products, alternative milk ( $1 \%)$ and alternative milk products $(0 \%)$ did not greatly contribute to dietary iodine, in any dietary groups, in either year.

In 2016-2017, the iodine contribution of alternative milks was significantly greater in vegans and vegetarians $(P \leq 0.001$, $P=0 \cdot 016)$. Alternative meats provided significantly greater contribution to dietary iodine in vegans compared with omnivores $(P=0 \cdot 018)$. Seaweed supplied a significantly greater iodine contribution to the diets of vegans compared with omnivores $(P=0 \cdot 040)$. Multivitamin supplements provided significantly greater iodine to the diets of vegans compared with omnivores and vegetarians $(P \leq 0.001, P=0.033)$.

In both years, the contribution of fruit and vegetables to dietary iodine was greater for vegans than omnivores $(P=0.001$ and 0.029$)$. In 2019, breads, grains and pulses and

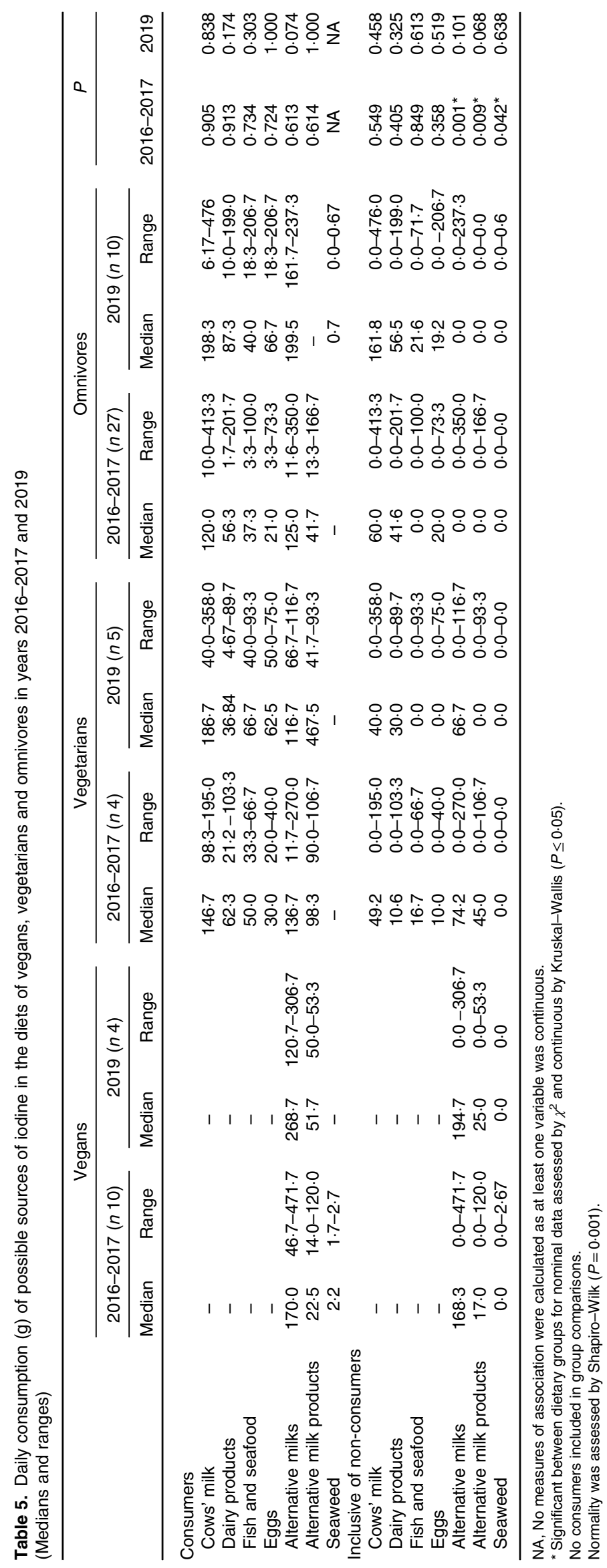

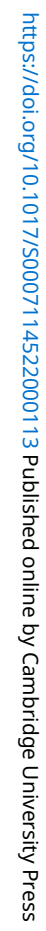


Table 6. Percentage (\%) iodine intake from different food groups in vegans, vegetarians and omnivores in years 2016-2017 and 2019. Inclusive of both consumers and non-consumers (Median percentages and ranges)

\begin{tabular}{|c|c|c|c|c|c|c|c|c|c|c|c|c|c|c|}
\hline \multicolumn{15}{|l|}{ Percentage iodine intake (\%) } \\
\hline & \multicolumn{4}{|c|}{ Vegans } & \multicolumn{4}{|c|}{ Vegetarians } & \multicolumn{4}{|c|}{ Omnivores } & \multicolumn{2}{|c|}{$P$} \\
\hline & \multicolumn{2}{|c|}{ 2016-2017 (n 10) } & \multicolumn{2}{|c|}{$2019(n 4)$} & \multicolumn{2}{|c|}{ 2016-2017 (n 4) } & \multicolumn{2}{|c|}{$2019(n 5)$} & \multicolumn{2}{|c|}{ 2016-2017 (n 27) } & \multicolumn{2}{|c|}{$2019(n 10)$} & \multirow[b]{2}{*}{$\begin{array}{l}2016- \\
2017\end{array}$} & \multirow[b]{2}{*}{2019} \\
\hline & $\begin{array}{c}\text { Median } \\
\text { percentage }\end{array}$ & Range & $\begin{array}{c}\text { Median } \\
\text { percentage }\end{array}$ & Range & $\begin{array}{c}\text { Median } \\
\text { percentage }\end{array}$ & Range & $\begin{array}{c}\text { Median } \\
\text { percentage }\end{array}$ & Range & $\begin{array}{c}\text { Median } \\
\text { percentage }\end{array}$ & Range & $\begin{array}{c}\text { Median } \\
\text { percentage }\end{array}$ & Range & & \\
\hline \multicolumn{15}{|l|}{ Food group } \\
\hline Cows' milk & - & & - & & 9.5 & $0.0-65.0$ & $14 \cdot 0$ & $0.0-74.9$ & $21 \cdot 0$ & $0.0-65.0$ & 23.5 & $0.0-51.6$ & 0.697 & 0.704 \\
\hline Dairy products & - & & - & & 0.0 & $0.0-0.0$ & 3.3 & $0.0-58.0$ & 0.0 & $0.0-41.0$ & 1.8 & $0.0-43 \cdot 8$ & 0.130 & 0.708 \\
\hline Fish and seafood & - & & - & & 0.9 & $0.0-2 \cdot 2$ & 0.0 & $0.0-15.8$ & 0.0 & $0.4-85.0$ & $12 \cdot 0$ & $0.0-47.5$ & 0.573 & 0.184 \\
\hline Eggs & - & & - & & 6.8 & $0.0-14.4$ & 0.0 & $0.0-28.0$ & 9.8 & $0.0-35.7$ & 11.7 & $0.0-29 \cdot 3$ & 0.512 & 0.343 \\
\hline Alternative milks & 0.6 & $0.0-16 \cdot 7$ & 0.6 & $0.0-3 \cdot 6$ & 0.3 & $0.1-38.3$ & 0.0 & $0.0-1.4$ & 0.0 & $0.0-60.4$ & 0.0 & $0.0-1.9$ & $0.001^{*}$ & 0.129 \\
\hline Alternative milk products & 0.0 & $0.0-3.4$ & 0.0 & $0.0-36.3$ & 0.0 & $0.0-0.0$ & 0.0 & $0.0-6 \cdot 8$ & 0.0 & $0.0-1.3$ & 0.0 & $0.0-0.0$ & 0.210 & 0.114 \\
\hline Meat and poultry & - & & - & & - & & - & & $5 \cdot 3$ & $0.0-63 \cdot 9$ & $6 \cdot 7$ & $0 \cdot 0-16 \cdot 3$ & NA & NA \\
\hline Alternative meat & 1.6 & $0.0-51.6$ & $4 \cdot 3$ & $0.0-24.8$ & 4.4 & $0.0-16.6$ & 0.0 & $0.0-0.9$ & 0.0 & $0.0-11.3$ & 0.0 & $0.0-0.0$ & $0.007^{*}$ & 0.057 \\
\hline Fruit and vegetables & 21.3 & $2 \cdot 9-76.9$ & $26 \cdot 8$ & $7.7-69.4$ & $9 \cdot 1$ & $8 \cdot 1-21 \cdot 1$ & 8.8 & $1 \cdot 1-93 \cdot 6$ & 5.9 & $0.5-33 \cdot 6$ & $2 \cdot 7$ & $1.0-8.0$ & $0.001^{*}$ & $0.025^{\star}$ \\
\hline $\begin{array}{l}\text { Breads, grains, pulses, } \\
\text { etc. }\end{array}$ & $5 \cdot 0$ & $1 \cdot 9-36.9$ & $21 \cdot 9$ & $17 \cdot 8-45 \cdot 6$ & $6 \cdot 0$ & $0 \cdot 8-27 \cdot 3$ & $2 \cdot 7$ & $0.0-12.5$ & $2 \cdot 8$ & $0 \cdot 0-20 \cdot 0$ & $3 \cdot 0$ & $0.0-8 \cdot 0$ & $0 \cdot 105$ & $0.012^{*}$ \\
\hline $\begin{array}{l}\text { Snacks, crisps, cakes } \\
\text { and nuts/seeds }\end{array}$ & $3 \cdot 6$ & $0 \cdot 0-58.9$ & 11.4 & $0 \cdot 0-37 \cdot 8$ & $2 \cdot 6$ & $1 \cdot 3-18 \cdot 8$ & $5 \cdot 7$ & $0.0-28.5$ & $2 \cdot 7$ & $0 \cdot 0-16 \cdot 8$ & $1 \cdot 3$ & $0.0-35.0$ & 0.253 & 0.633 \\
\hline Drinks & 0.3 & $0.0-58.9$ & 0.3 & $0.0-26.1$ & 0.0 & $0.0-36.4$ & 0.0 & $0.0-0.4$ & 0.0 & $0.0-2 \cdot 0$ & 0.0 & $0.0-0.0$ & 0.172 & $0.009^{*}$ \\
\hline Salt and spices & 0.0 & $0.0-2 \cdot 7$ & 0.1 & $0.0-0.5$ & 0.3 & $0.0-0.5$ & 0.0 & $0.0-0.8$ & 0.0 & $0.0-5.5$ & 0.0 & $0.0-2 \cdot 6$ & 0.371 & 0.869 \\
\hline lodised salt & 0.0 & $0.0-0.0$ & 0.0 & $0.0-0.0$ & 0.0 & $0.0-0.0$ & 0.0 & $0.0-0.0$ & 0.0 & $0.0-50.0$ & 0.0 & $0.0-0.0$ & 0.588 & 1.000 \\
\hline Seaweed & 0.0 & $0.0-79.0$ & 0.0 & $0.0-0.0$ & 0.0 & $0.0-0.0$ & 0.0 & $0.0-0.0$ & 0.0 & $0.0-0.0$ & 0.0 & $0.0-8 \cdot 0$ & $0.042^{*}$ & 0.638 \\
\hline Supplements & $2 \cdot 0$ & $0.0-86.6$ & 0.0 & 0.00 .0 & 0.0 & $0.0-0.0$ & 0.0 & $0.0-0.0$ & 0.0 & $0.0-0.0$ & 0.0 & $0.0-42 \cdot 0$ & $0.001^{*}$ & 0.638 \\
\hline
\end{tabular}

* Significant between dietary groups by Kruskal-Wallis $(P \leq 0.05)$.

Normality was assessed by Shapiro-Wilk $(P=0.001)$ 
drinks contributed significantly greater iodine to the diet of vegans than omnivores $(P=0.011$ and 0.007$)$.

Iodised salt was only consumed by one female participant in 2016-2017 following an omnivorous diet.

\section{Supplement usage}

Supplement usage was determined by FFQ. Overall, $42 \%$ of participants recorded consumption of a dietary supplement, either daily, weekly or sporadically. The most frequently used supplement for all groups was $\mathrm{B}_{12}(27 \%)$, followed by non-iodine-containing multivitamin formulations (17\%) and vitamin D (12\%). Multivitamins containing iodine were consumed by $12 \%$ of participants providing an average of $140 \mu \mathrm{g} / \mathrm{d}$ to dietary iodine. Seaweed supplements kelp and/or kombu were consumed by two omnivores in 2019, providing an average iodine intake estimate of $1541 \mu \mathrm{g} / \mathrm{d}$.

When comparing supplement use between years, the only significant difference observed was that vegans supplemented to a greater extent than omnivores in 2016-2017 $(P=0 \cdot 001)$. The iodine content provided by all consumed supplements differed according to dietary group in 2016-2017 $(P=0 \cdot 013)$ but not $2019(P=0.910)$. The iodine content of supplements consumed by vegetarians in 2016-2017 was significantly lower than those consumed by omnivores $(P=0 \cdot 022)$. Pearson's $\chi^{2}$ was used to assess iodine-containing supplement consumption (providing $>20 \mu \mathrm{g} / \mathrm{d}$ ) by dietary group.

A significantly greater proportion of vegetarians consumed iodine-containing supplements in 2016-2017 $(P=0.009)$ but not $2019(P=0.942)$. While supplement usage was recorded by participants in FFQ, only four participants recorded consumption in their FD.

\section{lodine status}

Iodine status assessed by UIC is presented in Fig. 3. Nine participants did not provide a urine sample (2016-2017, $n$ 8; $2019, n$ 1). In both years, omnivores had the greatest UIC (2016-2017, $79 \cdot 4 \mu \mathrm{g} / \mathrm{l} ; 2019,72 \cdot 4 \mu \mathrm{g} / \mathrm{l})$, followed by vegetarians $7 \cdot 32,2017-2016) \mu \mathrm{g} / \mathrm{l} ; 2019,13.4 \mu \mathrm{g} / \mathrm{l})$ and the lowest was recorded in vegans $(2016-2017,31 \cdot 2 \mu \mathrm{g} / \mathrm{l} ; 2019,12 \cdot 2 \mu \mathrm{g} / \mathrm{l})$. In 2016-2017, omnivores had significantly greater median UIC than vegans $(P=0.003)$ but not vegetarians $(P=0.083)$. A similar trend was observed in 2019, where omnivores had significantly higher median UIC than vegans and vegetarians $(P=0.029$ and $0.044)$. The greatest variation in UIC (inter-quartile range) was observed for omnivores in 2016-2017 and 2019 (76.3-100.9), compared with vegans $(30 \cdot 5-36 \cdot 5)$ and vegetarians (33.3-43.6).

None of the samples given by vegan participants in either years, or vegetarians in 2016-2017, was above the cut-off for iodine adequacy $(100 \mu \mathrm{g} / \mathrm{l})$. Vegans and vegetarians had median values signifying severe deficiency $(20-49 \mu \mathrm{g} / \mathrm{l})$ in both years studied.

The relationship between iodine intake from iodine-rich food sources and UIC, independent of dietary group, was assessed (Table 7). In 2016-2017, UIC increased with greater intake of cows' milk and dairy products $(r 0.512, P=0.030, r 0.530$, $P=0.013)$. This was not apparent in $2019(r-0.173, P=0.612$, $r-0.056, P=0.863$ ).

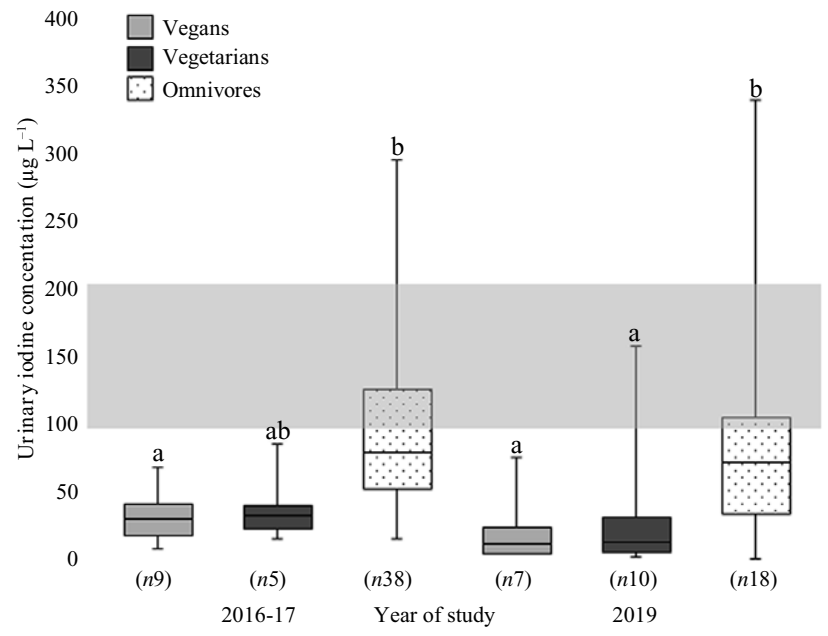

Fig. 3. lodine status of vegans, vegetarians and omnivores by urinary iodine concentration (UIC). Shaded areas show the proportion of participants within the WHO adequate range for median UIC $(100 \mu \mathrm{g} / \mathrm{l})$. Bars show variation (minimum and maximum). Different letters ( $a, b$ and $c$ ) represent significant differences among dietary groups, whereby $a>b, a b=a, a b=b, a>c, b>c$ and $a b>c(P=0.05)$ (Kruskal-Wallis test).

Table 7. Correlation coefficients between urinary iodine concentration (UIC) and sources of dietary iodine provided by food diary (FD) estimates, thyroid related micronutrients and iodine knowledge

\begin{tabular}{|c|c|c|c|c|}
\hline & \multicolumn{4}{|c|}{ UIC $(\mu g / l)$} \\
\hline & $\begin{array}{c}2016-2017 \\
(n 52)\end{array}$ & $P$ & $\begin{array}{l}2019 \\
(n 35)\end{array}$ & $P$ \\
\hline \multicolumn{5}{|l|}{ Food group (g/d) } \\
\hline Cows' milk & 0.512 & $0.030^{\star}$ & -0.173 & 0.612 \\
\hline Dairy products & 0.530 & $0.013^{*}$ & 0.056 & 0.863 \\
\hline Fish and seafood & -0.025 & 0.936 & $0 \cdot 100$ & 0.797 \\
\hline Eggs & -0.246 & 0.258 & -0.357 & 0.385 \\
\hline Alternative milk & 0.093 & 0.722 & -0.575 & 0.136 \\
\hline Alternative milk products & 0.454 & 0.160 & -0.400 & 0.600 \\
\hline \multicolumn{5}{|l|}{ Thyroid-related micronutrients } \\
\hline $\mathrm{Fe}$ & $-0.311^{*}$ & 0.025 & -0.024 & 0.888 \\
\hline $\mathrm{Se}$ & -0.136 & 0.335 & 0.192 & 0.262 \\
\hline Vitamin A & $-0.318^{*}$ & 0.022 & -0.078 & 0.653 \\
\hline \multicolumn{5}{|l|}{ lodine knowledge } \\
\hline $\begin{array}{l}\text { No. of correct symptoms identified } \\
\text { associated with deficiency }\end{array}$ & -0.037 & 0.814 & -0.292 & 0.084 \\
\hline $\begin{array}{l}\text { No. of correctly identified } \\
\text { iodine-rich food sources }\end{array}$ & $-0 \cdot 129$ & 0.423 & 0.060 & 0.727 \\
\hline $\begin{array}{l}\text { Total incorrect answers to iodine } \\
\text { knowledge questions }\end{array}$ & -0.037 & 0.816 & 0.216 & 0.206 \\
\hline Total iodine knowledge score & -0.050 & 0.751 & 0.230 & 0.178 \\
\hline
\end{tabular}

* Significant between dietary groups assessed by Spearman's correlation $(P \leq 0.05)$.

Consumption of milk alternatives and milk alternative products had no relationship with UIC in both years (2016-2017, $r 0.093, P=0.722, r 0.454, P=0 \cdot 160,2019, r-0.575, P=0.136$, $r-0.400, P=0 \cdot 600)$. Many varieties of alternative milk were fortified with vitamins and minerals; however, fewer than $12 \%$ $(2 / 17)$ of varieties were fortified with iodine. Iodine-fortified alternative milks provided an average of $47.6 \mu \mathrm{g} / 200 \mathrm{ml}$ portion of iodine (compared with $85 \mu \mathrm{g} / 200 \mathrm{ml}$ cows' milk) ${ }^{(21)}$. 


\section{lodine knowledge}

Iodine knowledge was poor in both years (Table 8), with median knowledge scores of 3 (2016-2017) and 5 (2019) reported out of a total of 17 . There was no difference in total iodine knowledge scores between dietary groups (2016-2017, $P=0.219 ; 2019, P=0.532$ ).

Most participants stated awareness of the importance of adequate dietary iodine intake. However, more than half of participants 'did not know' or were unable to correctly identify a health condition related to iodine deficiency. The most common symptom identified was goitre or enlargement of the thyroid gland, followed by cretinism. Other symptoms recognised included: tiredness, being sensitive to cold or weight gain.

A considerable selection of participants could not recognise the main food sources of iodine in the UK diet (dairy and whitefish). Many participants perceived foods such as leafy green vegetables and oily fish to be iodine rich. Overall, there was no significant difference in knowledge of iodine-rich foods between different dietary groups. However, vegetarians in 2016-2017 had significantly better knowledge of the role of cows' milk as a good source of iodine $(P=0.007)$.

Other demographics such as age were assessed as predictors of iodine knowledge. Younger participants tended to have lower iodine knowledge scores in 2016-2017 ( $r 0.409, P=0 \cdot 004)$. However, no relationship existed between age and iodine knowledge in $2019(r 0.409, P=0.529)$.

\section{Discussion}

To the best of our knowledge, this is the first study to monitor iodine in different dietary groups at two time points. In support of our hypothesis and conclusions from previous research ${ }^{(31)}$, we show that achievement of adequate iodine intake and status remains problematic for those following vegan and vegetarian diets. Our research also indicates that many university students may be vulnerable to iodine deficiency regardless of dietary practice. In 2014, the Scientific Advisory Committee on Nutrition reported on the current state of iodine nutrition in the UK, identifying vegans and vegetarians as a subgroup with increased risk of iodine deficiency ${ }^{(16)}$. Since publication, only one study has specifically addressed iodine in these diets in the $\mathrm{UK}^{(39)}$.

\section{Dietary intake}

Our results confirm that those not consuming animal-derived foods continue to have lower dietary iodine intake. Although our study contains a relatively small unbalanced sample of vegans and vegetarians in both years of study and may be subject to a high prevalence of under-reporting, estimated average dietary intake for vegans and vegetarians was below the Lower Reference Nutrient Intake of $70 \mu \mathrm{g} / \mathrm{d}$ using FD data. This was consistent with current data comparing iodine between dietary groups in the $\mathrm{UK}^{(39,51,54-56)}$, Europe ${ }^{(32,33,35-38,57-64)}$ and the USA ${ }^{(65)}$. When iodine requirements are not met, thyroid hormone synthesis is disrupted ${ }^{(2)}$. Persistent mild-moderate deficiency may put strain on the thyroid gland, stimulating thyroid stimulating hormone independent growth and thyroid autonomy ${ }^{(66)}$. Individuals experiencing thyroid autonomy at a young age may continue to have altered thyroid function in later life, even if adequate iodine intake is resumed ${ }^{(66)}$. Vegans and vegetarian diets that do not provide adequate iodine are a concern given that meat-free diets are often frequented by women of childbearing age (18-34 years) ${ }^{(67)}$. Although there is limited recent evidence among UK vegans for the presence of low iodine compromised pregnancies ${ }^{(68)}$, the rapidly expanding population comprising an increasing proportion of those less attentive to dietary requirements (REF) increases the number of individuals at greater risk of iodine deficiency in pregnancy and associated consequences for the developing fetus ${ }^{(68)}$. Adequate iodine intake is essential for those considering future pregnancy, as intra-thyroidal stores must be maximised before conception to facilitate fetal growth and neurological development ${ }^{(69-71)}$. Removing the possibility of pregnancy, those with increased risk should be shielded from the consequences of poor iodine nutrition. In both years of study, individuals following vegan diets had very low iodine intake (2016-2017, $47.6 \mu \mathrm{g} / \mathrm{d}, 17.3 \mu \mathrm{g} / \mathrm{d}$ ). This is of significant concern as dietary intake $<50 \mu \mathrm{g} / \mathrm{d}$ can potentiate the development of endemic goitre and hypothyroidism ${ }^{(5)}$. Although clinical manifestations are rare in Western nations experiencing mild-to-moderate iodine deficiency (UK), studies have observed meat-free diets be associated with the occurrence of iodine deficiency disor$\operatorname{ders}^{(72-74)}$. In both years of study, all dietary groups had median iodine intake below the current RNI $(140 \mu \mathrm{g} / \mathrm{d})$, highlighting the difficulty in achieving adequate iodine intake on any diet ${ }^{(75)}$.

Various challenges are associated with dietary assessment methods including accurate recall, memory retrieval and recording duration ${ }^{(76-78)}$. We selected two dietary methods to measure iodine intake, a 3-d FD and iodine-specific FFQ. FD typically underestimate usual dietary intake, whereas FFQ frequently overestimate ${ }^{(79,80)}$. In both years, the FFQ indicated that median dietary intake was above the RNI for vegetarians and omnivores, while FD estimates were below the RNI. The disparity in estimates may be due to different periods of recording ( 6 months $v .3 \mathrm{~d}$ ). Additionally, the FFQ covered the top food sources of iodine in the UK (cows' milk, dairy, eggs, fish and seafood), possible non-animal sources applicable for vegans and foods that are rarely consumed such as seaweed. The FFQ did not include other possible sources of iodine, for example, fruits, vegetables, grains, etc. that did contribute to dietary intake for all groups. Shortening the FFQ to provide limited food choices may have resulted in overestimation of items that are not frequently consumed or perhaps iodine-rich food items were not covered in the time covered by $\mathrm{FD}^{(80)}$. Due to methodological challenges associated with FFQ, we are unable to establish if iodine intake over time ( 6 months) is indeed adequate in our cohort. We have focused on FD estimates for our analysis as these records reflect recent iodine intake and are likely to correspond more closely to $\mathrm{UIC}^{(6)}$.

In Western diets, iodine is incorporated from adventitious sources such as iodine feed supplements and iodophors used in the dairy industry along with differing food practices between producers $^{(81)}$. Hence, cows' milk and milk products are good sources of iodine. One portion of cows' milk (200 ml) may 
Table 8. Baseline record of iodine knowledge (\%) by dietary group in years 2016-2017 and 2019* (Medians and ranges)

\begin{tabular}{|c|c|c|c|c|c|c|c|c|c|c|c|c|c|c|}
\hline \multirow[b]{3}{*}{ Responses } & \multicolumn{4}{|c|}{ Vegans } & \multicolumn{4}{|c|}{ Vegetarians } & \multicolumn{4}{|c|}{ Omnivores } & \multicolumn{2}{|l|}{$P$} \\
\hline & \multicolumn{2}{|c|}{ 2016-2017 (n 12) } & \multicolumn{2}{|c|}{$2019(n 7)$} & \multicolumn{2}{|c|}{ 2016-2017 (n 5) } & \multicolumn{2}{|c|}{$2019(n 10)$} & \multicolumn{2}{|c|}{ 2016-2017 (n 32) } & \multicolumn{2}{|c|}{$2019(n 18)$} & \multirow[b]{2}{*}{ 2016-2017 } & \multirow[b]{2}{*}{2019} \\
\hline & Median & Range & Median & Range & Median & Range & Median & Range & Median & Range & Median & Range & & \\
\hline \multicolumn{15}{|c|}{ Awareness of the importance of adequate dietary intake } \\
\hline Yes & 41.7 & & $85 \cdot 7$ & & $80 \cdot 0$ & & $100 \cdot 0$ & & 71.9 & & 89.5 & & 0.132 & 0.508 \\
\hline No & $58 \cdot 3$ & & 14.3 & & $20 \cdot 0$ & & 0.0 & & 28.1 & & 10.5 & & & \\
\hline \multicolumn{15}{|l|}{ Symptoms correctly identified } \\
\hline Yes & 41.7 & & 42.9 & & $60 \cdot 0$ & & $60 \cdot 0$ & & 46.9 & & $42 \cdot 1$ & & 0.788 & 0.635 \\
\hline No & $58 \cdot 3$ & & 57.1 & & $40 \cdot 0$ & & $40 \cdot 0$ & & $53 \cdot 1$ & & 57.9 & & & \\
\hline \multicolumn{15}{|l|}{ Knowledge of iodine deficiency symptoms } \\
\hline Compromised growth & 0.0 & & 0.0 & & 0.0 & & $10 \cdot 0$ & & 0.0 & & 5.3 & & NA & - \\
\hline Goitre/enlargement of the thyroid gland & $16 \cdot 7$ & & 42.9 & & $20 \cdot 0$ & & 40.0 & & $25 \cdot 0$ & & $26 \cdot 3$ & & 0.832 & - \\
\hline Neurological impairment & $8 \cdot 3$ & & 0.0 & & $20 \cdot 0$ & & 0.0 & & 12.5 & & $5 \cdot 3$ & & 0.797 & - \\
\hline Cretinism & $16 \cdot 7$ & & 0.0 & & $60 \cdot 0$ & & $10 \cdot 0$ & & 21.9 & & 5.3 & & 0.141 & - \\
\hline Reduced thyroid function & $25 \cdot 0$ & & 0.0 & & 0.0 & & $10 \cdot 0$ & & $3 \cdot 1$ & & 0.0 & & 0.048 & - \\
\hline Hypothyroidism & $8 \cdot 3$ & & 14.3 & & 40 & & 0.0 & & 12.5 & & $5 \cdot 3$ & & 0.209 & - \\
\hline Other & 0.0 & & 28.6 & & 0.0 & & $10 \cdot 0$ & & 0.0 & & 0.0 & & NA & - \\
\hline Do not know/no response & 0.0 & & $57 \cdot 1$ & & 0.0 & & $40 \cdot 0$ & & 0.0 & & 57.9 & & NA & - \\
\hline \multicolumn{15}{|c|}{ Understanding of the importance of iodine in pregnancy and infancy } \\
\hline Yes & $25 \cdot 0$ & & 28.6 & & $40 \cdot 0$ & & $60 \cdot 0$ & & 43.8 & & 36.8 & & 0.523 & 0.357 \\
\hline No & $75 \cdot 0$ & & 71.4 & & $60 \cdot 0$ & & $40 \cdot 0$ & & $56 \cdot 3$ & & $63 \cdot 2$ & & & \\
\hline \multicolumn{15}{|c|}{ Perceptions of the main food sources of iodine in the UK diet } \\
\hline Cows' milk & 33.3 & & $42 \cdot 9$ & & $100 \cdot 0$ & & $60 \cdot 0$ & & 38.7 & & 47.4 & & 0.026 & 0.742 \\
\hline Organic cows' milk & $25 \cdot 0$ & & 28.6 & & 40.0 & & $40 \cdot 0$ & & $75 \cdot 0$ & & $47 \cdot 4$ & & 0.772 & 0.684 \\
\hline Yogurt & 33.3 & & 28.6 & & $60 \cdot 0$ & & $10 \cdot 0$ & & $75 \cdot 0$ & & $26 \cdot 3$ & & 0.280 & 0.546 \\
\hline Whitefish & $25 \cdot 0$ & & 57.1 & & $80 \cdot 0$ & & $40 \cdot 0$ & & $50 \cdot 0$ & & $63 \cdot 2$ & & 0.099 & 0.489 \\
\hline Oily fish & 50.0 & & 28.6 & & 40.0 & & $20 \cdot 0$ & & 40.6 & & 52.6 & & 0.663 & 0.190 \\
\hline Sea salt & 33.3 & & 71.4 & & $60 \cdot 0$ & & $50 \cdot 0$ & & $56 \cdot 3$ & & $47 \cdot 4$ & & 0.590 & 0.540 \\
\hline Table salt & 41.7 & & $42 \cdot 9$ & & $40 \cdot 0$ & & 37.5 & & $53 \cdot 1$ & & 10.5 & & 0.928 & 0.128 \\
\hline Leafy green vegetables & $50 \cdot 0$ & & 71.4 & & $60 \cdot 0$ & & 60.0 & & 43.8 & & 57.9 & & 0.909 & 0.818 \\
\hline Wholemeal bread & 33.3 & & 28.6 & & $20 \cdot 0$ & & $10 \cdot 0$ & & 68.8 & & 10.5 & & 0.855 & 0.457 \\
\hline \multicolumn{15}{|l|}{ Total iodine knowledge score } \\
\hline Total score & 1.5 & $17 \cdot 0$ & $6 \cdot 0$ & 8.0 & 7.0 & $7 \cdot 0$ & 6.5 & $7 \cdot 0$ & 3.0 & $10 \cdot 0$ & $5 \cdot 0$ & $14 \cdot 0$ & 0.219 & 0.532 \\
\hline
\end{tabular}

$\mathrm{NA}$, no measures of association were calculated as at least one variable was continuous.

* Significant between dietary groups for nominal data assessed by $\chi^{2}$ and continuous by Kruskal-Wallis $(P \leq 0.05)$.

Normaliy was acossed by $\chi^{2}$ as

Normality was assessed by Shapiro-Wilk $(P=0.001)$. 
provide an average iodine concentration up to around $85.4 \mu \mathrm{g}$, although this is subject to seasonal variation ${ }^{(81)}$. In the current study, cows' milk and dairy products were positively associated with UIC in 2016-2017, suggesting their importance as sources of dietary iodine. Contrary to recent findings ${ }^{(82,83)}$, consumption of cows' milk exhibited no relationship with UIC in 2019. This finding may be explained by lower cows' milk intake in our cohort paralleling recent UK data which show that national dairy product consumption has reduced, particularly among younger people ${ }^{(18)}$. The majority of our study cohort comprised young adult females, a group in whom milk reduction is particularly noticeable ${ }^{(18,84)}$.

In the UK, there has been a sizable increase in the availability and popularity of non-dairy alternative milks (e.g. soya, oat and almond, etc.). Research by Mintel identified that adult household consumption of alternative milks increased from $14 \%$ in 2017 to $23 \%$ in $2019^{(18)}$. Displacement of iodine-containing cows' milk may increase the risk of deficiency. Label-based analysis conducted in 2015 revealed that alternative milks available in the UK had an average iodine content that is $1-5 \%$ of that of cows' milk, unless fortified ${ }^{(21)}$. We found that milk alternative and milk alternative product consumption had no relationship with UIC in 2016-2017 or 2019. Our findings did not match those observed in UK woman of childbearing age who were consumers of soya milk and a recent analysis of the National Diet and Nutrition Survey (2014-2017) which indicated that iodine nutrition was significantly lower in those who regularly consumed milk alternatives ${ }^{(11,83)}$. This study also showed intake of alternative milks to be significantly greater in vegans than vegetarians and omnivores. In our study, milk alternative consumption was not limited to vegan participants and was consumed by all dietary groups. Iodine-fortified milks were not greatly consumed, in either cohort, perhaps due to cost or low availability in the UK or lack of iodine awareness at the time of study. In 2016-2017, the iodine contribution of alternative milks appeared to be significant in the diets of vegans and vegetarians despite having a low iodine content. The iodine intake of vegans and vegetarians in our study was so low that the proportion contributed by foods that are not considered good sources of iodine (alternative milks, alternative meats, fruit, vegetables, breads, grains, pulses and drinks) appeared significant even though the absolute quantity was small. Given that it is likely that vegan and vegetarian influence on the food sector will continue to grow, individuals relying on alternative milk products to meet iodine requirements must be advised to select fortified varieties or to consume iodine from other food sources or supplements.

Milk is often consumed daily, whereas fish and seafood are not consumed as frequently and may not always be included in dietary records. Apparent elevated consumption of fish among vegetarians in 2016-2017 was due to the inclusion of a number of pescatarians in this group. In both years, average consumption of fish (for consumers) was greater than average fish consumption among adults in the UK between 30-60 g/week ${ }^{(85)}$. However, we did not see the expected positive relationship between UIC and fish and seafood consumption, presumably due to the low number of consumers across all groups. Fish intake in the UK is low, and thus may not serve as a good source of iodine for the general population. Barriers to fish intake include: cost, availability, cooking knowledge and palatability ${ }^{(86)}$.

The UK currently does not have a universal iodised salt programme ${ }^{(28)}$. Only one omnivore in 2016-2017 recorded consuming iodised salt in $3 \mathrm{~d}$ of records, contributing largely to iodine intake (61\%). Despite using iodised salt, the intake of this individual was below recommended intake of $150 \mu \mathrm{g} / \mathrm{d}$ $(119 \cdot 3 \mu \mathrm{g} / \mathrm{d})$. Vegan and vegetarian dietary choices are often linked with engagement in healthier behaviours and have been found to have lower salt intake compared with other groups ${ }^{(87)}$. Iodised salt is not routinely available from supermarkets for public purchasing, and varieties that are offered tend to be expensive compared with regular table salt ${ }^{(28)}$. Participants were not specifically asked to record salt added to meals and consequently, as suggested by previous work ${ }^{(88)}$, estimates of salt intake are likely to be low.

None of our participants indicated suffering from celiac disease; however, we cannot rule out the presence of undiagnosed disease. Iodine absorption in those with celiac disease is impaired compared with a healthy population and so those with disease coupled with restriction of iodine-rich foods may further exacerbate deficiency ${ }^{(89)}$. Specific diagnoses of celiac disease were beyond the scope of this study, but the likelihood of a significant impact of undiagnosed disease on our findings is low.

\section{Supplements}

In regions where no universal iodised salt coverage exists, iodine supplementation is particularly useful for prevention of deficiency $^{(11,90)}$. Supplement use was widely adopted in vegan groups in our study, yet most consumed supplements were non-iodine containing. The most frequently used supplement for all groups was $\mathrm{B}_{12}(27 \%)$, followed by non-iodine-containing multivitamin formulations (17\%). Since restrictive diets increase the risk of nutritional deficiencies $\left(\mathrm{B}_{12}\right.$, vitamin $\mathrm{D}, \mathrm{Zn}$, fatty acids, etc. $)^{(54,91)}$, individuals may consume micronutrient complexes over concerns for dietary adequacy. One participant, an omnivorous male in 2019, had dietary intake above the criteria for iodine excess ( $>300 \mu \mathrm{g} / \mathrm{d}$ ) according to FD data ${ }^{(6)}$, likely owing to consumption of a diet rich in cows' milk, dairy products, eggs and fish alongside daily use of iodine-containing micronutrient supplements. Improved awareness of iodinecontaining supplements to populations not consuming iodinerich foods is required.

Seaweed is a very rich and sustainable source of iodine. The iodine content of seaweed species can vary between $60 \mu \mathrm{g} \mathrm{100/g}$ to $624500 \mu \mathrm{g} 100 / \mathrm{g}$ (dry weight) ${ }^{(92)}$. Currently, seaweed is not recommended to improve iodine due to potential adverse effects relating to over-consumption ${ }^{(7)}$, with regular intake of seaweeds providing $>45 \mu \mathrm{g} / \mathrm{g}$ of iodine shown to compromise thyroid function ${ }^{(93)}$. Despite this, research has shown low-level seaweed supplementation to improve status of iodine-insufficient individuals in the UK and Europe $^{(37,51,55,56,59)}$. Seaweed has been suggested as a possible source of iodine for vegans ${ }^{(92)}$ but has been shown to frequently contribute to excessive iodine intake ${ }^{(31)}$. In the present study, seaweed supplements did provide an additional $1541 \mu \mathrm{g} / \mathrm{d}$ to 
dietary intake of two omnivores. Values at this level would exceed the upper tolerable limits of iodine and could lead to the development of alternative thyroid disorders ${ }^{(94)}$. Seaweed products are becoming more widely accepted in the $\mathrm{UK}^{(95)}$. To prevent excess associated with seaweed consumption products should be routinely monitored and their iodine content disclosed. Additionally, the risks involved with supplementing seaweeds should be communicated.

\section{lodine status}

Despite low sample sizes, the present study aligns with existing studies signifying that UK adults, particularly those following vegan and vegetarian diets, are at risk of iodine deficiency ${ }^{(39,51,54-56)}$. The iodine status of omnivores was significantly greater than vegans in both years and vegetarians in 2019. The UIC values for all dietary groups in our study were lower than those of the UK population. Nationally representative data collected in accordance with years of our study (2016-2017 to 2018-2019) recorded median UIC of $98 \mu \mathrm{g} / \mathrm{l}$ for women of childbearing age (19-49 years) and $106 \mu \mathrm{g} / \mathrm{l}$ for adults (19-64 years) ${ }^{(22)}$. However, omnivorous participants presented values signifying mild deficiency and both vegans and vegetarians had values within the criteria for moderate deficiency in 2016-2017, and severe in 2019. Worryingly, this result is indicative of a time-related decline in iodine status. Aligning with national trends, whereby, UIC averages fell between years 2014 and 2019 in both adults (3\%), and women of childbearing age $(9 \%)^{(22)}$.

UIC is the internationally recognised criteria for measuring population iodine status ${ }^{(6)}$. Spot samples are criticised for their inability to precisely detect mild-to-moderate iodine deficiency (median UIC $>50 \mu \mathrm{g} / \mathrm{l}$ ) due to diurnal variation in $\mathrm{UIC}^{(96,97)}$, which are lowest between 08.00-11.00 hours and slowly increase after 12.00 hours, before peaking $4-5 \mathrm{~h}$ after feeding. Our study was strengthened by concurrent collection of spot samples. By noon most participants would have consumed a meal; hence, UIC values would be above baseline. UIC has been found to be significantly lower in non-breakfast consuming individuals ${ }^{(97)}$. Given that numerous studies have concluded that breakfast skipping is widespread among young adults at universities $^{(98)}$, this may have contributed to lower UIC in our study.

\section{lodine knowledge}

Sufficient iodine knowledge has been shown to be positively correlated with iodine nutrition with iodine intake and status $^{(14,15)}$. Our study was populated by university students and staff; therefore, most participants were of a high education level. We found no difference in total iodine scores between the dietary groups, suggesting that dietary practice was not a predictor of iodine knowledge in this cohort. Limited research exists investigating the difference in dietary knowledge between vegans, vegetarians and omnivores. Iodine knowledge scores were lower than that recorded for UK females $(2 \cdot 1$ (SD $0 \cdot 8)$ out of a possible 8$)^{(14)}$ and were lower in younger participants in 2016-2017. This may reflect the stage of education, such that first year undergraduate students may be less aware of the role of iodine in the diet, but this was not addressed in our study. Iodine awareness in general was low, with most participants being unable to identify a health condition related to iodine deficiency. Our findings also indicated that misconceptions exist in our population regarding which foods are iodine rich. Many selected leafy green vegetables and oily fish as good sources of iodine. Awareness of foods contribution to iodine varied by dietary group. A larger proportion of vegetarians in our study were able to correctly identify cows' milk as a useful iodine source, which did not translate to greater dietary intake. Understanding the role of cows' milk in iodine provision varies across studies. In the UK, $16 \%$ of respondents showed good understanding and Australia 9\%, while this rose to $47 \%$ in a Norwegian cohort ${ }^{(13,14,99)}$. Other foods rich in iodine (such as whitefish and yogurt) had variable responses between dietary groups. Iodine knowledge may not translate to behaviour change in more restrictive dietary groups, for example, it is unlikely that strict vegans will decide to consume animal products based on iodine content. Our results suggest that public health strategies are needed to improve public awareness of iodine and good sources of iodine for those not consuming cows' milk, dairy, whitefish or eggs need to be communicated, in addition to choosing foods that are fortified with iodine.

\section{Energy intake}

We found no significant association between energy and iodine intake; however, in both years of study, average daily energy intake was below the current UK recommendations for weight maintenance (female: $2000 \mathrm{kcal}$; male: $2500 \mathrm{kcal}$ ) despite most participants recording BMI within the healthy range ${ }^{(47)}$. In 20162017, vegetarians had BMI values that were significantly lower than omnivores. However, in our current study average energy intake (kcal) did not differ between dietary groups (2016-2017, $P=0.438 ; 2019, P=0.802$ ). Lowered energy intake may be attributed to high prevalence of under-reporting in our study. The incidence of under-reporting ranges between 18 and 54\% in dietary studies ${ }^{(100)}$. In our study, the rate of under-reporting was much greater (73\%). This finding could be attributed to common determinants of misreporting. Our sample was largely female, and women tend to report energy intake to be significantly lower than daily recommendations ${ }^{(100)}$. We did not record PAL as part of our study; therefore, EI:EE cut-offs are likely to be inaccurate. Misreporting of iodine-containing foods may have impacted our collected results. Healthy foods (fruit and vegetables) are often over-reported and females classed as under-reporters have been shown to consume significantly lower levels of foods rich in iodine, including cows' milk, dairy products, eggs and fats ${ }^{(101)}$.

\section{Study limitations}

There are few validated FFQ specifically assessing iodine intake in Western or UK populations, of which none is tailored for vegans $^{(102-104)}$. Despite our FFQ being based on that used in the EPIC study, which has been extensively validated ${ }^{(44)}$, the FFQ used in our study was not validated following modifications and so inaccuracies may occur due to difficulties distinguishing between categories. The Nutritics software, used to analyse FD, 
uses food tables to estimate average intake and cannot account for variability in iodine content within food ${ }^{(81)}$. The iodine content of foods is not adjusted per season to constitute changes in content throughout the year ${ }^{(81)}$. Cows' milk iodine concentration is highest in winter and since our data were collected in different seasons, winter 2016-2017 and summer 2019, the data may be subject to seasonal variation ${ }^{(81)}$. Additionally, many manufacturers of vegan products cannot accurately provide measures of iodine ${ }^{(55)}$.

Median UIC is the principle method for assessing population iodine status, as up to $90 \%$ of absorbed iodine is excreted in the urine. Several factors may influence UIC measured by spot samples, including daily variation in the iodine content of recently consumed foods and circadian rhythms ${ }^{(97)}$. Moreover, UIC varies by recent fluid intake as UIC is expressed per volume of urine ${ }^{(105)}$. We were unable to account for fluid intake as creatinine was not measured and many participants did not record fluid intake within FD.

Finally, inclusion of pescatarians and individuals who had recently transitioned onto a vegan diet as part of the 'vegetarians' dietary group may not be reflective of the restrictions included in these groups. To retain sample size, even vegans and vegetarians with low dietary adherence (i.e. occasional consumption of cows' milk/dairy) were included into analysis. Lastly, most participants were students and so our cohort is therefore likely to be highly motivated and well-educated.

\section{Conclusion}

Vegans and vegetarians are a subgroup at increased risk of iodine deficiency. Regardless of dietary choice, the exclusion or substitution of iodine-rich animal products appears to act as a barrier to achieving iodine recommendations. Individuals following restricted diets should be encouraged to select iodinecontaining supplements or fortified foods. At policy level, mandatory fortification of products mimicking cows' milk may be beneficial given the popularity of these foods and potential for them to be a useful vehicle to improve iodine intake. Formal education focusing on providing accurate and reliable information to vulnerable groups (vegans, vegetarians and young women) should be considered at national level. Further monitoring and assessment of the consequences of lowered iodine intake in individuals implementing strict dietary choices is required.

\section{Supplementary material}

For supplementary material accompanying this paper visit https://doi.org/10.1017/S0007114522000113

\section{Acknowledgements}

The authors thank the BBSRC for funding and the Division of Food, Nutrition and Dietetics at The University of Nottingham for backing.

This research was supported by a BBSRC doctoral training program studentship, grant number BB/M008770/1. The BBSRC had no role in the design, analysis or writing of this article.
Conceptualisation, E. R. E., L. J. C. and S. J. M. W.; methodology, E. R. E., L. J. C. and S. J. M. W.; formal analysis, E. R. E., L. J. C. and S. J. M. W.; investigation, E. R. E., L. J. C., M. Z., H. B., J. M., V. H. and S. J. M. W.; writing - original draft preparation, E. R. E.; writing - review and editing, E. R. E., L. J. C. and S. J. M. W.; visualisation, E. R. E.; supervision, L. J. C. and S. W.; funding acquisition, E. R. E., L. J. C. and S. J. M. W. All authors have read and agreed to the published version of the manuscript.

There are no conflicts of interest.

\section{References}

1. Zimmermann MB \& Boelaert K (2015) Iodine deficiency and thyroid disorders. Lancet Diabetes Endocrinol 3, 286-295.

2. Ahad F \& Ganie SA (2010) Iodine, iodine metabolism and iodine deficiency disorders revisited. Indian J Endocrinol Metab 14, 13-17.

3. Bath SC \& Rayman MP (2015) A review of the iodine status of UK pregnant women and its implications for the offspring. Environ Geochem Health 37, 619-629.

4. O'Kane SM, Mulhern MS, Pourshahidi LK, et al. (2018) Micronutrients, iodine status and concentrations of thyroid hormones: a systematic review. Nutr Rev 76, 418-431.

5. Kapil U (2007) Health consequences of iodine deficiency. Sultan Qaboos Univ Med J 7, 267-272.

6. VMNIS (2013) Vitamin and Mineral Nutrition Information System Urinary Iodine Concentrations for Determining Iodine Status in Populations. https://www.who.int/publications/i/item/WHONMH-NHD-EPG-13.1 (accessed February 2020).

7. Zimmermann MB \& Andersson M (2012) Assessment of iodine nutrition in populations: past, present, and future. Nutr Rev 70, 553-570.

8. Nutrition Requirements (2019) https://www.nutrition.org. uk/healthy-sustainable-diets/vitamins-and-minerals/?level= Health\%20professional (accessed August 2021).

9. Vanderpump MPJ, Lazarus JH, Smyth PP, et al. (2011) Iodine status of UK schoolgirls: a cross-sectional survey. Lancet 377 , 2007-2012.

10. The Lancet Diabetes Endocrinology (2016) Iodine deficiency in the UK: grabbing the low-hanging fruit. Lancet Diabetes Endocrinol 4, 469.

11. Bath SC, Walter A, Taylor A, et al. (2014) Iodine deficiency in pregnant women living in the South East of the UK: the influence of diet and nutritional supplements on iodine status. Br J Nutr 111, 1622-1631.

12. Derbyshire E (2018) Micronutrient intakes of British adults across mid-life: a secondary analysis of the UK national diet and nutrition survey. Front Nutr 5, 55.

13. Henjum S, Brantsæter AL, Kurniasari A, et al. (2018) Suboptimal iodine status and low iodine knowledge in young Norwegian women. Nutrients 10, 941.

14. O'Kane SM, Pourshahidi LK, Farren KM, et al. (2016) Iodine knowledge is positively associated with dietary iodine intake among women of childbearing age in the UK and Ireland. $\mathrm{Br} J$ Nutr 116, 1728-1735.

15. Garnweidner-Holme L, Aakre I, Lilleengen AM, et al. (2017) Knowledge about iodine in pregnant and lactating women in the Oslo area, Norway. Nutrients 9, 493.

16. GOV.UK (2014) SACN Statement on Iodine and Health. https://www.gov.uk/government/publications/sacn-statementon-iodine-and-health-2014 (accessed October 2019).

17. Bath S \& Rayman M (2016) British Dietetic Association: Iodine Food Fact Sheet. https://www.bda.uk.com/resource/iodine. html (accessed May 2017). 
18. Mintel.com (2019) A Quarter of Brits Use Plant-Based Milk https://www.mintel.com/press-centre/food-and-drink/milkingthe-vegan-trend-a-quarter-23-of-brits-use-plant-based-milk (accessed April 2021)

19. GOV.UK (2019) Family Food 2017-2018. https://www.gov. uk/government/statistics/family-food-201718/family-food201718 (accessed April 2021).

20. GOV.UK (2021) Family Food 2018-2019. https://www.gov. uk/government/statistics/family-food-201819 （accessed August 2021).

21. Bath SC, Hill S, Infante HG, et al. (2017) Iodine concentration of milk-alternative drinks available in the UK in comparison with cows' milk. Br J Nutr 118, 525-532.

22. GOV.UK (2018) NDNS: Results from Years 7 and 8 (Combined). https://www.gov.uk/government/statistics/ndnsresults-from-years-7-and-8-combined (accessed May 2020).

23. Smyth PPA \& Karger S (2021) Iodine, seaweed, and the thyroid. Eur Thyroid J 10, 101-108.

24. Yeh TS, Hung NH \& Lin TC (2014) Analysis of iodine content in seaweed by GC-ECD and estimation of iodine intake. J Food Drug Anal 22, 189-196.

25. Leung AM \& Braverman LE (2014) Consequences of excess iodine. Nat Rev Endocrinol 10, 136-142.

26. Zimmermann MB \& Andersson M (2012) Current Opinion Update on Iodine Status Worldwide. www.iccidd.org (accessed April 2021)

27. Wu T, Liu GJ, Li P, et al. (2002) Iodised salt for preventing iodine deficiency disorders. The Cochrane Database of Systematic Reviews, issue 3, CD003204. https://pubmed.ncbi. nlm.nih.gov/12137681/.

28. Bath SC, Button S \& Rayman MP (2014) Availability of iodised table salt in the UK - is it likely to influence population iodine intake? Public Health Nutr 17, 450-454.

29. Action on Salt (2014) Main Sources of Salt in the UK Diet. http://www.actiononsalt.org.uk/uk-salt-reduction/salt-intakein-the-uk/main-sources-of-salt-in-the-uk-diet/ (accessed May 2020).

30. Ni Mhurchu C, Capelin C, Dunford EK, et al. (2011) Sodium content of processed foods in the United Kingdom: analysis of 44,000 foods purchased by 21,000 households. Am J Clin Nutr 93, 594-600

31. Eveleigh ER, Coneyworth LJ, Avery A, et al. (2020) Vegans, vegetarians, and omnivores: How does dietary choice influence iodine intake? A systematic review. Nutrients 12, 1606.

32. Menzel J, Abraham K, Stangl GI, et al. (2021) Vegan diet and bone health - results from the cross-sectional RBVD study. Nutrients 13, 685

33. Groufh-Jacobsen S, Hess SY, Aakre I, et al. (2020) Vegans, vegetarians and pescatarians are at risk of iodine deficiency in Norway. Nutrients 12, 1-13.

34. Deutsches Ärzteblatt: Archiv (2020) "Vitamin and Mineral Status in a Vegan Diet". https://www.aerzteblatt.de/pdf.asp? id $=215079$ (accessed April 2021).

35. García-Morant A, Cortés-Castell E, Palazón-Bru A, et al. (2020) Macronutrients and micronutrients in Spanish adult vegans (Mediterranean population). Nutr Hosp 37, 549-558.

36. Schüpbach R, Wegmüller R, Berguerand C, et al. (2017) Micronutrient status and intake in omnivores, vegetarians and vegans in Switzerland. Eur J Nutr 56, 283-293.

37. Waldmann A, Koschizke JW, Leitzmann C, et al. (2003) Dietary intakes and lifestyle factors of a vegan population in Germany: results from the German vegan study. Eur J Clin Nutr 57, 947-955.

38. Elorinne A-L, Alfthan G, Erlund I, et al. (2016) Food and nutrient intake and nutritional status of Finnish vegans and non-vegetarians. PLOS ONE 11, e0148235.
39. Fallon N \& Dillon SA (2020) Low intakes of iodine and selenium amongst vegan and vegetarian women highlight a potential nutritional vulnerability. Front Nutr 7, 72 .

40. Nutritics (2019) Nutrition Analysis, Menu Management \& Labelling Software. https://www.nutritics.com/p/home (accessed April 2021).

41. GOV.UK (2015) Composition of Foods Integrated Dataset (CoFID). https://www.gov.uk/government/publications/ composition-of-foods-integrated-dataset-cofid (accessed April 2021).

42. GOV.UK (2020) NDNS: Results from Years 9 to 11 (2016 to 2017 and 2018 to 2019). -https://www.gov.uk/government/ statistics/ndns-results-from-years-9-to-11-2016-to-2017-and-2018to-2019 (accessed May 2020)

43. Online Surveys (2016) https://www.onlinesurveys.ac.uk/ (accessed September 2016).

44. EPIC Oxford (1997) Study Design, Ethics and Regulation. http://www.epic-oxford.org/methods/ (accessed September 2016).

45. Lennox A, Fitt E, Whitton C, et al. (2008) Appendix A. Dietary Data Collection and Editing (accessed April 2021).

46. Medical Research Council Collaborative Centre for Human Nutrition Research (MRC-HNR) (2008) National Diet and Nutrition Survey Food and Drink Diary. https://dapa-toolkit. $\mathrm{mrc} . \mathrm{ac} . u \mathrm{uk} / \mathrm{pdf} / \mathrm{Diet} /$ Food\%20Diaries/Food_diary_Adults_A5_ v3_Q4.pdf (accessed May 2021)

47. Body Mass Index (2016) https://www.who.int/data/gho/ data/themes/theme-details/GHO/body-mass-index-(bmi) (assessed April 2016)

48. Black AE (2000) Descriptors: diet; energy intake; validity. EurJ Clin Nutr 54, 395-404.

49. Goldberg GR \& Black AE (1998) Assessment of the validity of reported energy intakes - Review and recent developments. Scand J Nutr 42, 6-9.

50. Statista (2018) England: Adult's BMI by Gender/Age 2018. https://www.statista.com/statistics/375886/adult-s-body-massindex-by-gender-and-age-in-england/ (accessed April 2020).

51. Draper A, Lewis J, Malhotra N, et al. (1993) The energy and nutrient intakes of different types of vegetarian: a case for supplements? Br J Nutr 69, 3-19.

52. Sample Size Calculator (2019) https://clincalc.com/stats/ samplesize.aspx (accessed May 2021).

53. British Nutrition Foundation (2018) Energy Intake and Expenditure. https://www.nutrition.org.uk/index.php?option= com_content\&view $=$ article\&id=263: energyintake-andexpenditure $\&$ catid $=65 \&$ Itemid $=199 \&$ showall $=1 \&$ limitstart (accessed April 2021).

54. Davey GK, Spencer EA, Appleby PN, et al. (2002) EPICOxford: Lifestyle Characteristics and Nutrient Intakes in a Cohort of 33883 Meat-Eaters and 31546 Non Meat-Eaters in the UK. https://www.cambridge.org/core/services/aopcambridge-core/content/view/BF14D307B5A33B572CFB2A3050 410974/S1368980003000351a.pdf/epicoxfordlifestyle_ characteristics_and_nutrient_intakes_in_a_cohort_of_33_883 _meateaters_and_31_546_non_meateaters_in_the_uk.pdf (accessed June 2019).

55. Lightowler HJ \& Davies GJ (2002) Assessment of iodine intake in vegans: weighed dietary record $v$. duplicate portion technique. Eur J Clin Nutr 56, 765-770.

56. Lightowler HJ \& Davies GJ (1998) Iodine intake and iodine deficiency in vegans as assessed by the duplicate-portion technique and urinary iodine excretion. Br J Nutr 80, 529-535.

57. Allès B, Baudry J, Méjean C, et al. (2017) Comparison of sociodemographic and nutritional characteristics between self-reported vegetarians, vegans, and meat-eaters from the nutrinet-santé study. Nutrients $\mathbf{9}, 1023$. 
58. Henjum S, Brantsæter A, Kurniasari A, et al. (2018) Suboptimal iodine status and low iodine knowledge in young Norwegian women. Nutrients 10, 941.

59. Kristensen NB, Madsen ML, Hansen TH, et al. (2015) Intake of macro- and micronutrients in Danish vegans. Nutr J 14, 115.

60. Krajcovicová-Kudlácková M, Bucková K, Klimes I, et al. (2003) Iodine deficiency in vegetarians and vegans. Ann Nutr Metab 47, 183-185.

61. Nebl J, Schuchardt JP, Wasserfurth P, et al. (2019) Characterization, dietary habits and nutritional intake of omnivorous, lacto-ovo vegetarian and vegan runners - a pilot study. BMC Nutr 5, 1-14

62. Rauma AL, Törmälä ML, Nenonen M, et al. (1994) Iodine status in vegans consuming a living food diet. Nutr Res $\mathbf{1 4}$ 1789-1795.

63. Remer T, Neubert A \& Manz F (1999) Increased risk of iodine deficiency with vegetarian nutrition. BrJ Nutr 81, 45-49.

64. Weikert C, Trefflich I, Menzel J, et al. (2020) Versorgungsstatus mit vitaminen und mineralstoffen bei veganer ernährungsweise. Deutsch Arztebl Int 117, 575-582.

65. Leung AM, LaMar A, He X, et al. (2011) Iodine status and thyroid function of Boston-area vegetarians and vegans. J Clin Endocrinol Metab 96, E1303-E1307.

66. Chung HR (2014) Iodine and thyroid function. Ann Pediatr Endocrinol Metab 19, 8.

67. Statista (2019) Adults Following Vegan Diet by Gender GB 2019. https://www.statista.com/statistics/1062343/adultsfollowing-vegan-diet-in-great-britain-by-gender-and-age/ (accessed September 2019).

68. Dineva M, Fishpool H, Rayman MP, et al. (2020) Systematic review and meta-analysis of the effects of iodine supplementation on thyroid function and child neurodevelopment in mildly-to-moderately iodine-deficient pregnant women. $\mathrm{Am}$ J Clin Nutr 112, 389-412.

69. Zimmermann MB (2009) Iodine deficiency. Endocr Rev 30, 376-408.

70. Zimmermann MB (2011) Iodine deficiency in industrialized countries. Clin Endocrinol 75, 287-288.

71. Zimmermann MB (2011) The role of iodine in human growth and development. Semin Cell Dev Biol 22, 645-652.

72. Shaikh MG, Anderson JM, Hall SK, et al. (2003) Transient neonatal hypothyroidism due to a maternal vegan diet. J Pediatr Endocrinol Metab 16, 111-113.

73. Brooks MJ \& Post EM (2014) Acquired hypothyroidism due to iodine deficiency in an American child. J Pediatr Endocrinol Metab 27, 1233-1235.

74. Yeliosof O \& Silverman LA (2018) Veganism as a cause of iodine deficient hypothyroidism. J Pediatr Endocrinol Metab 31, 91-94.

75. Krela-Ka冈mierczak I, Czarnywojtek A, Skoracka K, et al. (2021) Is there an ideal diet to protect against iodine deficiency? Nutrients 13, 1-15.

76. Thornton K \& Villamor E (2016) Nutritional epidemiology. In Encyclopedia of Food and Health, pp. 104-107 [Benjamin Caballero, Paul M Finglas and Fidel Toldra, editors]. Cambridge, MA: Academic Press

77. Shim J-S, Oh K \& Kim HC (2014) Dietary assessment methods in epidemiologic studies. Epidemiol Health 36, e2014009.

78. NCBI Bookshelf (2002) Food-Based Assessment of Dietary Intake - Dietary Risk Assessment in the WIC Program. https://www.ncbi.nlm.nih.gov/books/NBK220560/?report= reader (accessed August 2021).

79. Wu Y, Chen W, Shen J, et al. (2018) Reproducible and reliable general semiquantitative food frequency questionnaire for evaluating iodine intake in Chinese children. Nutr Res $\mathbf{5 5}$, $72-80$.
80. Næess S, Aakre I, Kjellevold M, et al. (2019) Validation and reproducibility of a new iodine specific food frequency questionnaire for assessing iodine intake in Norwegian pregnant women. Nutr J 18, 1-12.

81. Bath SC, Button S \& Rayman MP (2012) Iodine concentration of organic and conventional milk: implications for iodine intake. Br J Nutr 107, 935-940.

82. O'Kane SM, Pourshahidi LK, Mulhern MS, et al. (2018) Cow milk consumption increases iodine status in women of childbearing age in a randomized controlled trial. $J$ Nutr 148, 401-408.

83. Dineva M, Rayman MP \& Bath SC (2020) Iodine status of consumers of milk-alternative drinks versus cows' milk: data from the UK national diet and nutrition survey. BrJ Nutr 79, E752.

84. Mintel.com (2019) UK Added Value in Dairy Drinks, Milk and Cream Industry Report. https://store.mintel.com/uk-addedvalue-in-dairy-drinks-milk-and-cream-market-report?ga $=2$. 94564700.1197200142.1588851528-2009417485.1588672425 (accessed May 2020).

85. National Diet and Nutrition Survey (2019) Time Trend and Income Analyses. A Survey Carried Out on Behalf of Public Health England and the Food Standards Agency. www. facebook.com/PublicHealthEngland (accessed April 2021).

86. Kranz S, Jones NRV \& Monsivais P (2017) Intake levels of fish in the UK paediatric population. Nutrients $\mathbf{9}, 392$.

87. Clarys P, Deliens T, Huybrechts I, et al. (2014) Comparison of nutritional quality of the vegan, vegetarian, semivegetarian, pesco-vegetarian and omnivorous diet. Nutrients 6, 1318-1332.

88. Condo D, Makrides M, Skeaff S, et al. (2015) Development and validation of an iodine-specific FFQ to estimate iodine intake in Australian pregnant women. Br J Nutr 113, 944-952.

89. Delvecchio M, Bizzoco F, Lapolla R, et al. (2021) Iodine absorption in celiac children: a longitudinal pilot study. Nutrients 13, 1-10.

90. Untoro J, Timmer A \& Schultink W (2010) The challenges of iodine supplementation: a public health programme perspective. Best Pract Res Clin Endocrinol Metab 24, 89-99.

91. Medawar E, Huhn S, Villringer A, et al. (2019) The effects of plant-based diets on the body and the brain: a systematic review. Transl Psychiatry 9, 226.

92. Cherry P, O'hara C, Magee PJ, et al. (2019) Risks and benefits of consuming edible seaweeds. Nutr Rev 77, 307-329.

93. Desideri D, Cantaluppi C, Ceccotto F, et al. (2016) Essential and toxic elements in seaweeds for human consumption. J Toxicol Environ Health A 79, 112-122.

94. Sá Monteiro M, Sloth J, Holdt S, et al. (2019) Analysis and risk assessment of seaweed. EFSA J 17, Suppl. 2, 170915.

95. Bouga M \& Combet E (2015) Emergence of seaweed and seaweed-containing foods in the UK: focus on labeling, iodine content, toxicity and nutrition. Foods $\mathbf{4}, 240-253$.

96. Andersen S, Pedersen KM, Pedersen IB, et al. (2001) Variations in urinary iodine excretion and thyroid function. A 1-year study in healthy men. EurJEndocrinol 144, 461-465.

97. Als C, Helbling A, Peter K, et al. (2000) Urinary iodine concentration follows a circadian rhythm: a study with 3023 spot urine samples in adults and children. J Clin Endocrinol Metab 85, 1367-1369.

98. Sprake EF, Russell JM, Cecil JE, et al. (2018) Dietary Patterns of University Students in the UK: A Cross-Sectional Study. https://doi.org/10.1186/s129370180398-y (accessed April 2021).

99. Charlton KE, Gemming L, Yeatman H, et al. (2010) Suboptimal iodine status of Australian pregnant women reflects poor knowledge and practices related to iodine nutrition. Nutrition 26, 963-968. 
100. Macdiarmid J \& Blundell J (1998) Assessing dietary intake: who, what and why of under-reporting. Nutr Res Rev 11, 231-253.

101. Bingham SA, Cassidy A, Cole TJ, et al. (1995) Validation of weighed records and other methods of dietary assessment using the $24 \mathrm{~h}$ urine nitrogen technique and other biological markers. Br J Nutr 73, 531-550.

102. Combet E \& Lean MEJ (2014) Validation of a short food frequency questionnaire specific for iodine in UK females of childbearing age. J Hum Nutr Diet 27, 599-605.
103. Condo D, Makrides M, Skeaff S, et al. (2015) Development and validation of an iodine-specific FFQ to estimate iodine intake in Australian pregnant women. $\mathrm{Br} J \mathrm{Nutr} \mathbf{1 1 3}$ 944-952.

104. Rasmussen LB, Ovesen L, Bülow I, et al. (2001) Evaluation of a semi-quantitative food frequency questionnaire to estimate iodine intake. Eur J Clin Nutr 55, 287-292.

105. Vejbjerg P, Knudsen N, Perrild H, et al. (2009) Estimation of iodine intake from various urinary iodine measurements in population studies. Thyroid 19, 1281-1286. 